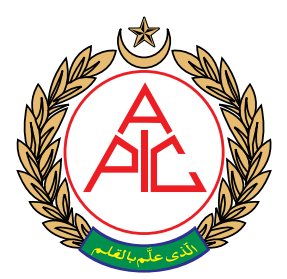

Injury Rehabilitation Specialist, MSKNeurology, Oslo, (Norway) 2 Department of Clinical and Experimental Medicine, Division of Rheumatology, University of Florence, AOU Careggi, Florence, (Italy) ${ }^{3}$ Director of Neurosurgery, Aashuman Hospital Dwarka Sector 10, New Delhi, (India)

Correspondence: Kjetil Larsen, Injury Rehabilitation Specialist, MSKNeurology, Oslo, (Norway); Tel.: +47 97545 192; E-mail: Kjetil@ MSKNeurology.com

Received: 30 November 2019;

Reviewed: 2, 6 February 2019;

Accepted: 27 February 2019

\section{Does thoracic outlet syndrome cause cerebrovascular hyperperfusion? Diagnostic markers for occult craniovascular congestion}

\author{
Kjetil Larsen, Felice C. Galluccio, MD, ${ }^{2}$ Sharma Karam Chand, \\ $\mathrm{MD}^{3}$
}

\begin{abstract}
Thoracic outlet syndrome (TOS) is known to be associated with diffuse craniological comorbidities (CCM), such as occipital headaches, migraines, vestibular dysfunction, tinnitus and fatigue. Conventionally, these problems have been suggested to be a manifestation of positional vertebrobasilar insufficiency. Angiography tends to be normal in TOS sufferers, however, and doppler ultrasonography of the vertebral artery fails to demonstrate severe flow reduction. TOS is attributed to the brachial plexus and subclavian artery being compressed in the interscalene triangle, costoclavicular or subpectoral passages. The vertebral and carotid arteries arise from subclavian artery proximal to the sites of obstruction in TOS. Numerous reports of resolved CCM post-scalenectomy and first-rib resection, despite lacking vertebral artery impairment, have been documented. TOS CCM, moreover, share many of the symptoms seen in systemic and intracranial hypertension. Reports of subclavian thromboembolus migrating to the head have been documented in incidences of TOS, showing the potential for flow retrogradation. We postulate that the blood prevented from entering the brachium due to distal subclavian compression, retrogrades to the brain via the carotid and vertebral arteries, resulting in craniovascular hyperperfusion and congestion.
\end{abstract}

Key words: Thoracic outlet syndrome; Cerebrovascular hyperperfusion; Idiopathic intracranial hypertension; Cerebrovascular hypertension; Hypertension; Migraine; Headache; Vertigo; Chronic fatigue syndrome; Myalgic encephalomyelitis

Abbreviations: Thoracic outlet syndrome: TOS, Vertebral artery: VA, Vertebrobasilar insufficiency: VBI, Cerebrovascular hyperperfusion: $\mathrm{CVH}$, Bloodbrain barrier: BBB, Myalgic encephalomyelitis: ME, "Time of flight": TOF,

Citation: Larsen K, Galluccio FC, Chand SK. Does thoracic outlet syndrome cause cerebrovascular hyperperfusion? Diagnostic markers for occult craniovascular congestion. Anaesth pain intensive care 2020;24(1)69-86. DOI: https://doi. org/10.35975/apic.v24i1.1230

\section{INTRODUCTION}

Thoracic outlet syndrome (TOS) is a common problem that has been implicated in many diffuse maladies, ${ }^{1,2}, 3,4,5$ amongst these, vestibular dysfunction, migraines, visual impairment, tinnitus and fatigue are commonly mentioned. Sanders $6,7,8$ states that up to $86 \%$ of TOS patients may have occipital ("hypertensive") headaches, but the relationship between TOS and migraines and its other cerebral co-morbidities are not well understood.9 In this regard, it has been postulated that vertebrobasilar insufficiency (VBI) caused by intermittent compression of the vertebral arteries may be the cause of these problems, as several studies have demonstrated flow velocity reduction upon 
full cervical rotation.5,7,10,11,12,13,14,15,16,17,18 Rotational occlusion of the vertebral artery (VA), however, is a rare incidence, and even when found, it may still be asymptomatic due to adequate contribution from its right or left counterpart. ${ }^{19,20}$ Even the carotid artery may be up to $70 \%$ stenosed and still be asymptomatic. ${ }^{21}$ Further, although maximal cervical rotation may theoretically obstruct the VA, the patient is unlikely to stay in such a position for long durations at a time, rendering the likelihood of its continuous implication in these issues doubtful. Finally, considering that the absolute majority of TOS patients suffer from cerebral co-morbidities without findings of conspicuous vascular compromise, and the fact that unilateral VA obstruction is rare and may even be asymptomatic, how likely is it really that these problems may be attributed to vertebrobasilar insufficiency?

Several researchers have studied the vertebral arteries during cervical rotation with ultrasonographic Doppler, and have demonstrated mild to moderate flow velocity changes, suggesting that positional hypoperfusion may occur. ${ }^{22,23}$ This appears to be a common finding upon cervical rotation, also in our own clinical practice. However, empirically, flow loss to the degree of ischemia is very rare. Moreover, it has been shown that there is a poor correlation between flow velocities, occlusion and VBI. ${ }^{24}$ Also, demonstrable flow velocity changes upon cervical rotation may represent normal and benign changes in luminal diameter with compensatory velocity accommodation, consistent with Pousille's law of flow continuity, and does therefore not necessarily suggest frank obstruction. ${ }^{24,25,26}$ Further, many patients with no proven brachial nor VA compromise still frequently resolve their cerebral co-morbidities post decompressive TOS surgery.6,27,28,29,30 Finally, obstruction in maximal rotation would likely cause positional symptoms rather than symptoms appearing spontaneously and often without a distinct pattern, as seen in Sell et al's ${ }^{10}$ case where the patient consistently developed unilateral blindness with excessive leftward rotation due to left-sided scalenogenic VA occlusion. Combined, it is the authors' opinion that the prior arguments strongly suggest attribution of these cerebral problems to an etiology other than that of VBI.

Contrarily, we have found that Doppler waveforms of patients with TOS may resemble those of patients with systemic hypertension, especially during cervical rotation, being evident by a slow systolic upstroke, rounded and blunted systolic peaks, with or without diastolic attenuation. We have found that hypertensive waveforms occur during ipsilateral cervical rotation and extension, but either improve or spontaneously resolve (unilaterally) with contralateral rotation and flexion. This, as the first-mentioned tightens the scalenus muscles and the latter relaxes them, thus increasing or decreasing brachial arterial resistance due to increased or decreased mechanical stress placed on the subclavian artery in the interscalene triangle. It is our belief that the distal obstruction of the subclavian artery caused by TOS prevents normal perfusion rates of the arm, and that the blood inhibited from entering the brachium is forced to retrograde into the nearest vessel of lesser resistance, i.e. the vertebral and carotid arteries, resulting in unior bilateral cerebrovascular hyperperfusion $(\mathrm{CVH})$.

\section{TOS' EFFECT ON HAEMODYNAMICS AND ITS IMPLICATIONS}

TOS is, conventionally, not regarded as a pathology that affects the cerebrum. However, many common complaints that patients with TOS have, are quite similar to those of intracranial hypertension and systemic hypertension. Headaches, fatigue, vestibular dysfunction, and more, are all well-known sequelae of all three pathological conditions. ${ }^{31,32,33}$ In severe incidences, syncope, ${ }^{34}$ seizures, ${ }^{35}$ or other sinister symptoms may develop. Currently, the cause of these co-morbidities in TOS remains unexplained.

Preexisting literature has shown that patients with TOS have developed thromboembolus that travelled retrograded from the subclavian artery to the head and caused stroke, ${ }^{36,37,38,39,40,41,42}$ demonstrating the potential for retrograde flow from subclavian to carotid artery in TOS patients. We postulate that the compression imposed on the distal subclavian artery in TOS not only inhibits some blood from entering the brachial artery, but that the obstructed blood reverts toward the head, resulting in, to some extent, continuous TOS-induced cerebrovascular hyperperfusion $(\mathrm{CVH})$. In this case, systemic blood pressures will generally be normal or may even be hypotensive. Cerebral MRI, venography, and angiographies will also appear normal, thus rendering this problem almost entirely occult, as there will be no conspicuous indicators of hypertension, despite the patient presenting with suggestive symptoms. Verily, the symptoms of TOS CVH are consistent with those of hypertension or even malign hypertension, but with normal systemic pressures.

The brain is very sensitive to both hypo- and hyperperfusion. To compensate for natural alterations in cerebral blood supply, cerebral autoregulation is an autonomic process which, as the name suggests, autoregulates flow rates and pressures in the cerebrovascular system, to maintain steady perfusion and pressure. The autonomic nervous system may reduce cerebrovascular pressures mainly by inducing intracranial and peripheral vasodilation, or by reducing the heart rate. Contrarily, pressures are increased by inducing vasoconstriction or by increasing the heart rate. In TOS, peripheral resistance is mechanically placed on the subclavian artery in 
the interscalene triangle, as well as costoclavicular and subpectoral spaces, ${ }^{2}$ and will, therefore, override brachial vasodilation as a regulatory mechanism. We believe that this causes a continuous increase in perfusion rates through the vertebral and carotid arteries, especially on the right side (as the right internal carotid artery branches off the innominate artery in the majority of the population whereas the left carotid generally branches off the aortic arch). There will be insufficient cerebral vasodilation available to cope for this continuous, abnormal increase in incoming blood volumes, often resulting in cerebrovascular congestion. Thus, in many incidences, as vasodilation fails to lower the pressures, cardiac output may be decreased, resulting in compensatory bradycardia or borderline bradycardia being induced by the autonomic nervous system. ${ }^{44,45}$ This may result in the paradoxical but common event where systemic hypotension and intracranial hypertension concomitantly develops, which seems to be especially prevalent in female TOS sufferers. Compatibly, in our experience, patients with TOS and debilitating cerebral co-morbidity frequently present with a resting heart rate between $50-60$ beats per minute despite being of non-suggestive [often poor] cardiovascular fitness levels.

With regards to implications, little existing evidence forelies for moderate degrees of cerebrovascular hyperperfusion, as seen in TOS. However, its many potential symptoms are consistent with those of systemic and intracranial hypertensive states. Headaches and migraines, chronic fatigue, and vestibular dysfunction are perhaps some of its most common sequelae. Tinnitus, both ordinary as well as pulsatile, is also common. Unilateral (or, rarely, bilateral), mild to moderate forms of hemifacial weakness or ptosis, dysarthria, aphasia, and amnesia, may also be seen, in many circumstances. Rarely, usually in incidences of cervical whiplash or concurrent [severe] anxiety disorder, sporadic syncope, ${ }^{34}$ narcolepsy and seizures ${ }^{35}$ may develop as well, as mentioned earlier. It is known that chronic hypertension may impair cerebral autoregulation. ${ }^{46,47}$ Continuous cerebrovascular hypertension may predispose the patient to aneurysm development, ${ }^{48}$ and intima-media thickening through the processed named by Miller as lipohyalinosis, ${ }^{49}$ which may result in unexpected strokes or hemorrhages. TOS symptoms are highly prevalent in migraine patients. This may explain why some of these patients are at higher risk for both ischemic as well as hemorrhagic strokes, ${ }^{50,51,52,53,54,55}$ and also present with seemingly idiopathic hypertensive retinal signs. ${ }^{56,57,58}$ Saxton et al. ${ }^{27}$ documented a case where a patient with migraine since childhood, whose symptoms exacerbated with neck extension and ipsilateral rotation and brachial elevation, and whose MRA demonstrated sole subclavian artery obstruction within the interscalene triangle, entirely resolved post scalenectomy. Research has also suggested that chronic hyperperfusion may result in deterioration of the blood-brain barrier (BBB). Deliberate BBB breakdown in animal experiments have shown that secondary seizures, epilepsy and neuronal damage may occur. ${ }^{59,60,61}$ It may also cause cerebral swelling and demyelination, $48,62,63,64$ Some authors have postulated that cerebral edema may be the underlying cause of pathologies such as multiple sclerosis, ${ }^{65,66}$ although this remains a controversial topic. Up to $69 \%$ of people living with multiple sclerosis also suffer from migraines. ${ }^{67}$ TOS CVH often causes pronounced fatigue, and is a common co-finding in patients with myalgic encephalomyelitis (ME) / chronic fatigue syndrome. We also believe that the compensatory cerebroarterial vasodilation that occurs in chronic $\mathrm{CVH}$ may play a role in postural orthostatic tachycardia syndrome, another common sub-component of ME.

\section{DIAGNOSTIC APPROACHES}

TOS-induced cerebrovascular hyperperfusion is a hidden disorder and may, perhaps, only be directly identified by intraluminal catheter measurements in the extracranial arteries. However, several subtle but indicative findings may be made non-invasively through various examinations, which will be discussed in this section. In cases where other etiologies of the patient's problems have been excluded, such as frank positional VA occlusion, systemic hypertension, intracranial masses, atherosclerosis or cerebral venous drainage-deficits (CVD) (e.g., thrombosis or highgrade cerebral venous sinus stenosis), and the patient is known to have TOS (regardless of whether or not the patient suffers from some degree of frank brachial ischemia), a potential presence of TOS-induced cerebrovascular hyperperfusion may be investigated. It is a common sequela in TOS patients. TOS CVH may also have a concurrent presence in patients who also carry other, more conspicuous pathologies such as systemic hypertension or CVD. It should also be noted that TOS CVH will be amplified by both of the latter conditions.

With regard to TOS itself, its elaborated diagnostic protocols are outside of the main scope of this article. However, we have used a modified version of Selmonosky's diagnostic triad ${ }^{68,69,70,71}$ to diagnose TOS on these patients: Clinical presentation should have common denominators with TOS' symptomology, although the brachial aspect may or may not be the most dominant ones. Chest pain, brachialgia, dyspnea, and periscapular pain are common symptoms in TOS. Myotome testing may frequently reveal weakness of the triceps, fifth finger, and finger abduction, as the inferior trunk of the brachial plexus lies more susceptible to compression in the costoclavicular space. There is usually severe pain elicited upon 
Morley's test and peripheral palpation of the radial and ulnar nerves in the medial and lateral aspects of the forearm. Moreover, naturally, craniological co-morbidities should present such as headaches, occipital headaches, migraine, tinnitus, vestibular dysfunction, or asthenia. There may or may not be positive vascular TOS tests such as Selmonosky's white hand sign, military brace (Halstead's) or Adson's tests, or by duplex ultrasound examination of the axillary artery, but it is important to note that the absence of brachial flow impairment does not exclude craniovascular involvement. Roos' test is usually positive and may also demonstrate post-exertional palmar paleness either uni- or bilaterally.

As stated, TOS CVH is an occult pathology, because vascular imaging will appear within normal limits. For example, ultrasound Doppler velocities as well as magnetic resonance angiography (MRA) of the intra- and extracranial arteries will appear normal, because these examinations conventionally aim to detect hypoperfusion rather than hyperperfusion. However, ultrasonography still plays an essential role in its diagnosis, but the diagnosis is made through a combination of clinical signs, symptomology, and qualitative Doppler waveform assessments rather than typical velocity measurements. MRA may demonstrate increased carotid contrast saturation and intensity upon raising of the arms (fig. 5) or even in a normal, supine position, suggesting hematogenous retrogradation and arterial congestion. Finally, fundoscopy may sometimes provide valuable, as retinal cotton wool spots, arteriolar constriction, snail tracks, or, in some incidences, papilledema may be present despite the lack of high brachial blood pressure $e^{56}$ or cerebrovenous compromise. Papillary elevation may also be seen with transorbital ultrasonography, and duplex evaluations of the central retinal artery may demonstrate hypertensive arterial waveforms.

Mild to moderate degrees of distal (i.e. stenosis distal to the vertebral artery's emanation) subclavian artery stenosis may be asymptomatic in many circumstances. 1 The arm is much less sensitive to changes in perfusion than the brain. Therefore, in TOS, cerebral symptoms may develop far prior to any symptoms of frank brachial ischemia, and thus a negative Doppler study of the axillary artery in TOS provocative positions does not exclude TOS CVH. One reason for this is that the brain's metabolic rate is quite constant relative to that of the brachium. Another important reason is that TOS usually causes intermittent and positional impingement of the thoracic outlet's neurovascular bundle, of course, depending on the degree of affliction. Either way, it will have a positional component of either improvement or exacerbation. Scapular retraction and depression narrows the costoclavicular passage and thus obstruct the subclavian artery or vein. ${ }^{72,73}$
Similarly, ipsilateral rotation and extension will tauten the scalenus anticus and may consequently obstruct the subclavian artery at its passage through the interscalene triangle. In contrast, to positionally decompress these spaces, the patient should be set into cervical contralateral rotation and flexion (if unilateral) or just in flexion if it is bilateral, with moderate scapular elevation and slight protraction.

\section{A. Cervical retraction and extension test}

The scalenus anticus muscle is a neck flexor, lateral cervical flexor and ipsilateral rotator. It will tauten significantly with cervical extension and ipsilateral rotation. Moreover, depression of the scapulae will further obstruct the costoclavicular passage and the subclavian vasculature. Patients with severe TOS will experience a rapid and substantial increase in perceived in tracranial pressures and pulsatility in neck extension. The increased pulsatility may be palpated and also noted by the clinician; it is often conspicuous when situated in the provocative position. Ipsilateral rotation will increase the pressures in the ipsilateral carotid and vertebral arteries, and ameliorate the contralateral side due to stretching of the ipsilateral and relaxation of the contralateral scalenus muscles. Usually, mere retraction of the neck is sufficient to demonstrate the problem, as seen in Figure 1.

Reiterated, compatible symptoms and clinical suspicion of TOS are identified before diagnosing TOS CVH; it is not rendered based on one single test. Other, direr potential etiologies should also be excluded. This test has limited value if used in solitude; a series of tests and clinical evaluations are necessary to get a clear image over the patient's situation.

\section{B. Doppler ultrasonography}

In hypertension, although the flow velocities may appear within normal limits, Doppler waveforms markedly change depending on pressure severity. It has been shown repeatedly that hypertensive patients tend to develop a less vertical systolic upstroke, i.e. delayed upstroke, ${ }^{74,75,76}$ rounding of the systolic peak, along with increased inclination in the diastolic descent, ${ }^{74,77,78}$ and thus an increase in pulsatility. ${ }^{74,79,80}$ Similar findings are usually seen in [milder] incidences of TOS induced CVH.

Figure 2: [Source:] Kohara et al.74 showed that slowed systolic upstrokes with rounded peaks and reduced diastolic velocities were common findings in patients with systemic hypertension.

Moderate cases of TOS induced $\mathrm{CVH}$ will frequently present with "pyramidal" systolic waveforms, ${ }^{81}$ i.e. increased pulsatility but with slow and somewhat dampened systolic upstrokes. Strong pulsatility usually correlates with the degree of hypertension. . $^{74,79,80}$ In very severe incidences, 


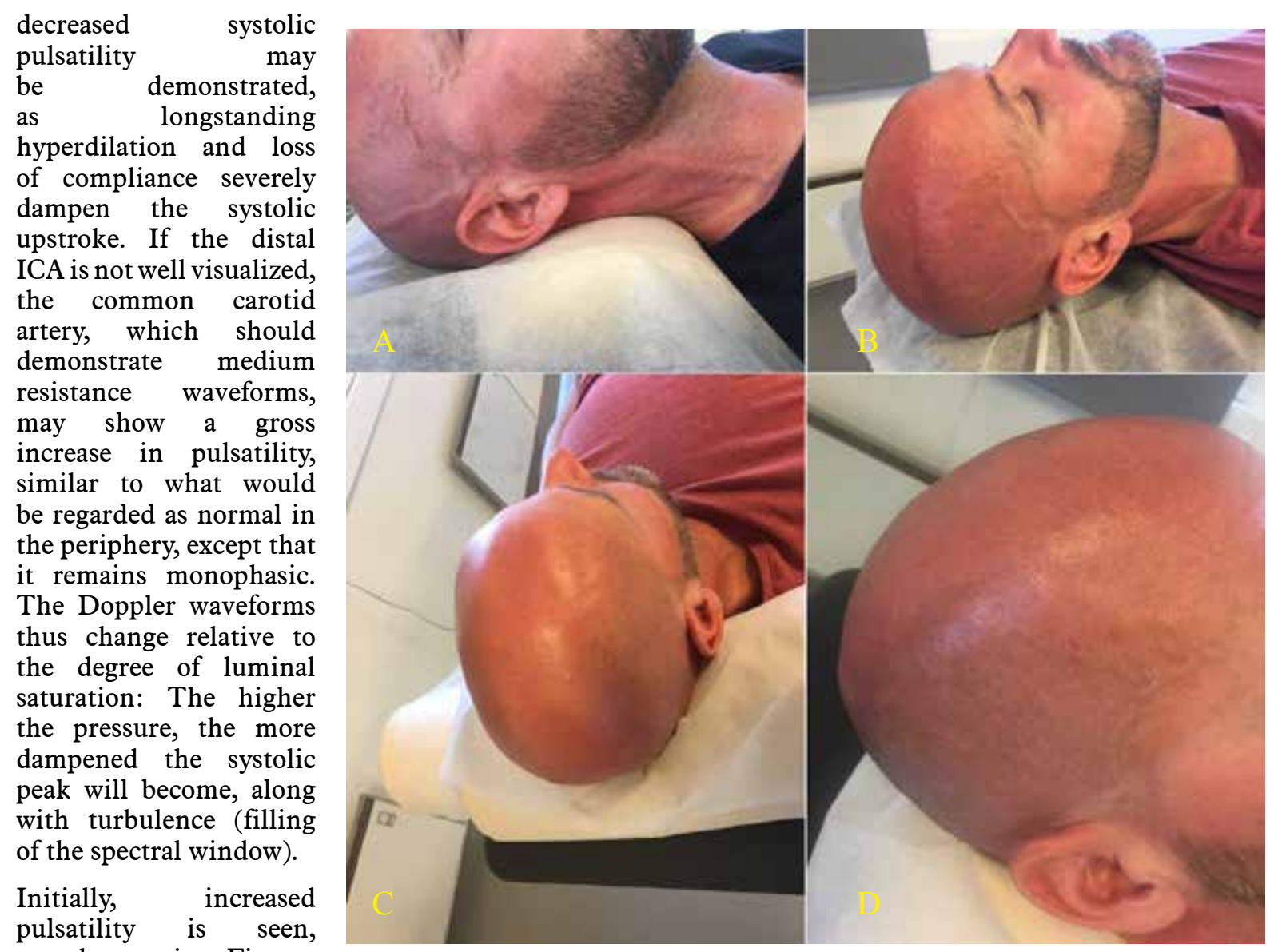
as shown in Figures 3 \& 4. However, as luminal compliance exceeds, severe systolic dampening may be visualized, as seen in Figure 5. Similar findings may be made for the VA, although, empirically, the vertebral arteries tend to appear normal more often than the carotid arteries. When examining the vertebral arteries for signs of $\mathrm{CVH}$, the distal V2, or distal V3 segments should be checked, as the congestion is greater and more evident proximal to the cranium. The external carotid artery Figure 1: A \& B images demonstrate significant dilation of the temporal arteries along with redness of the scalp and neck, in cervical extension (the pillow on the top left is very small and soft). The patient experiences a concomitant increase in carotid pulsatility, as is also palpable by the clinician. Bottom C \& D: Placing the patient in $45^{\circ}$ of cervical flexion (large, hard pillow) normalizes the carotid caliber and also remarkably reduces carotid pulsatility

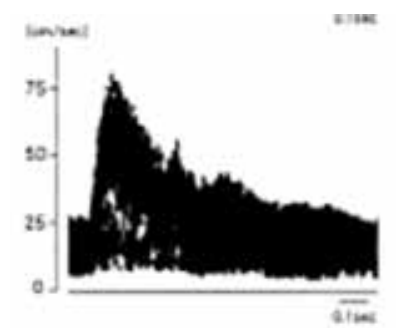

30 y.0. fernale

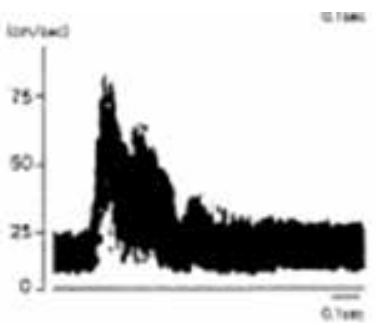

62 y.o. male

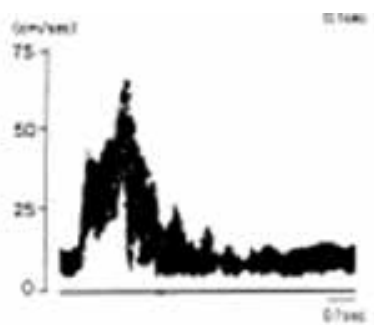

75 y.o. female

Figure 2: Shows that slowed systolic upstrokes with rounded peaks and reduced diastolic velocities were common findings in patients with systemic hypertension [Kohara et al. ${ }^{75}$ ]

may also show signs of

hypersaturation, indicated through dampening of the systolic peaks. In some of these patients, their carotid pulsatility may be so strong that it is challenging to hold the transducer steadily and acquire a good measurement.

There are usually two main, typical appearances seen in these patients - the ones with "pyramidal" systolic peaks, and those with severely dampened systolic peaks. The first-mentioned findings seem to indicate that there is some compliance of the lumen during systole, but the latter, i.e. loss of a delineable peak, most likely indicates loss of luminal compliance due to hypersaturation and pre-expansion. More research 


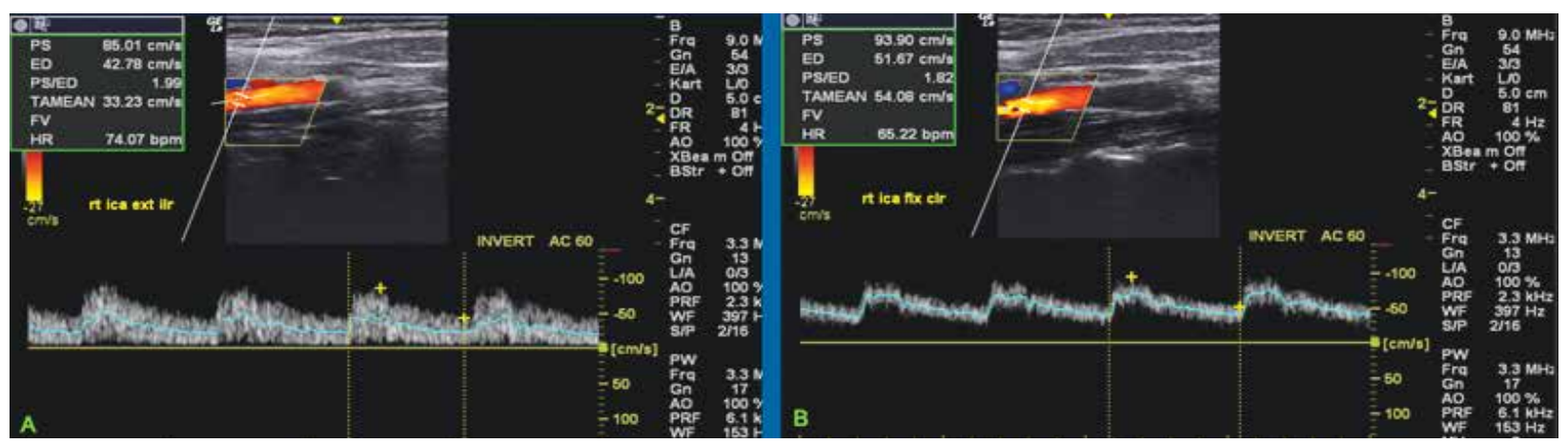

Figure 3: Here, we show the Doppler waveforms of a 40-year-old woman with frequent idiopathic syncope, chronic migraine, fatigue and upper extremity pain. Severe pain was elicited during Morley's test, and the patient had a presyncopy event shortly after. We were able to cancel the syncopal episode by turning her neck contralaterally and into slight flexion. The changes in waveform quality are apparent. In image A, severe turbulence (spectral filling) diffuse rounding of the systolic peak is seen. These waveforms are not tardus parvus; note the normal velocities. In image $B$, after setting the patient in cervical flexion and contralateral rotation, flow turbulence vanishes, and a very stable flow rate is seen. The systolic peak is now delineable, and time-averaged mean flow velocities almost double, as the distal vascular congestion has been [temporarily] resolved. Fundoscopy showed right-sided retinal arteriolar constriction. Brachial blood pressure was $127 / 83$.

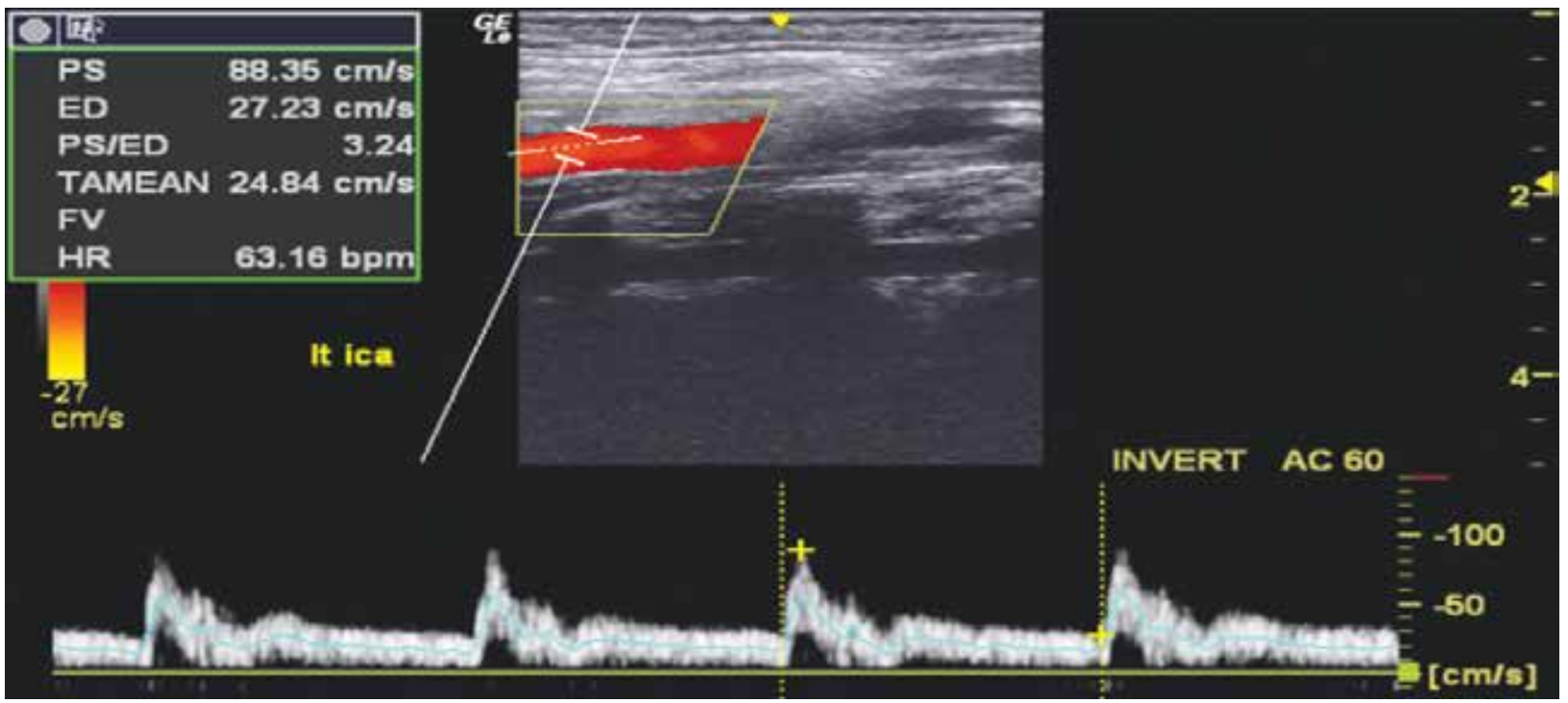

Figure 4: Pyramidal waveforms with a subtly slowed systolic upstroke and rapid diastolic declination (increased pulsatility) in a 34-year-old male patient with chronic fatigue, severe dizziness and periodic migraines, indicative of distal cerebrovascular congestion. This scan was done in a neutral cervical position.

is needed to confirm these hypotheses, however. We have found that patients with waveforms similar to those outlined in Kohara's ${ }^{74}$ paper are generally seen in patients with mild to moderate morbidity. In contrast, severe blunting of the systolic peak is often seen in patients with more severe cerebral issues such as seizures and frequent seemingly idiopathic syncopal events.

\section{Rotational vertebral artery compromise}

For the case of frank vertebrobasilar insufficiency: Strangulation of the VA by the scalenus anticus muscle is a rare but potentially sinister sequela of TOS. ${ }^{10,11,12,13,14,15,16,17,18}$ Similarly, bow hunter's syndrome (BHS) is yet another problem where the VA becomes compressed in the transverse vertebral foramen, either due to foraminal stenosis or atlantoaxial hypermobility. ${ }^{18,19,20}$ Empirically, at least at this point in time, we have not encountered frank rotational VBI in any of our TOS patients. Its existence is not disputed, however, but VBI should not be considered a common TOS sequela, as it is by some, today. Be that as it may, both of these problems are serious, but, thankfully, easily excludable through a dynamic Doppler ultrasonographic examination. To correctly interpret the examination, it is important to understand the essential yet subtle differences between near-occlusive "tardus parvus" waveforms, 
and $\mathrm{CVH}$ waveforms. Although they may resemble in waveform shapes, tardus parvus flow rates will often demonstrate very low systolic and enddiastolic velocities (generally systolic velocities below $60 \mathrm{~cm} /$ $\mathrm{s}^{21}$ ), and no focal plaque nor other stenotic causes may be demonstrated. MRA will appear abnormal in legitimate luminal stenosis, with post-stenotic tardus parvus waveforms. In $\mathrm{CVH}$, systolic velocities are dampened, but still within normal limits. The main frank abnormality found in $\mathrm{CVH}$ are waveform changes, not velocity changes. There is plentiful of diastolic flow in CVH. MRA will appear normal to be within normal parameters. Further, although the symptoms reported of VBI may be similar to those of severe $\mathrm{CVH}$, VBI is induced rotationally, whereas CVH is usually more constant. Sell et al. ${ }^{10}$ described a patient with rotational VBI in TOS who developed ipsilateral blindness every time he turned his head to the right. Dynamic angiography demonstrated occlusion of the right VA by scalenus anticus muscle, and she was cured after surgical decompression.

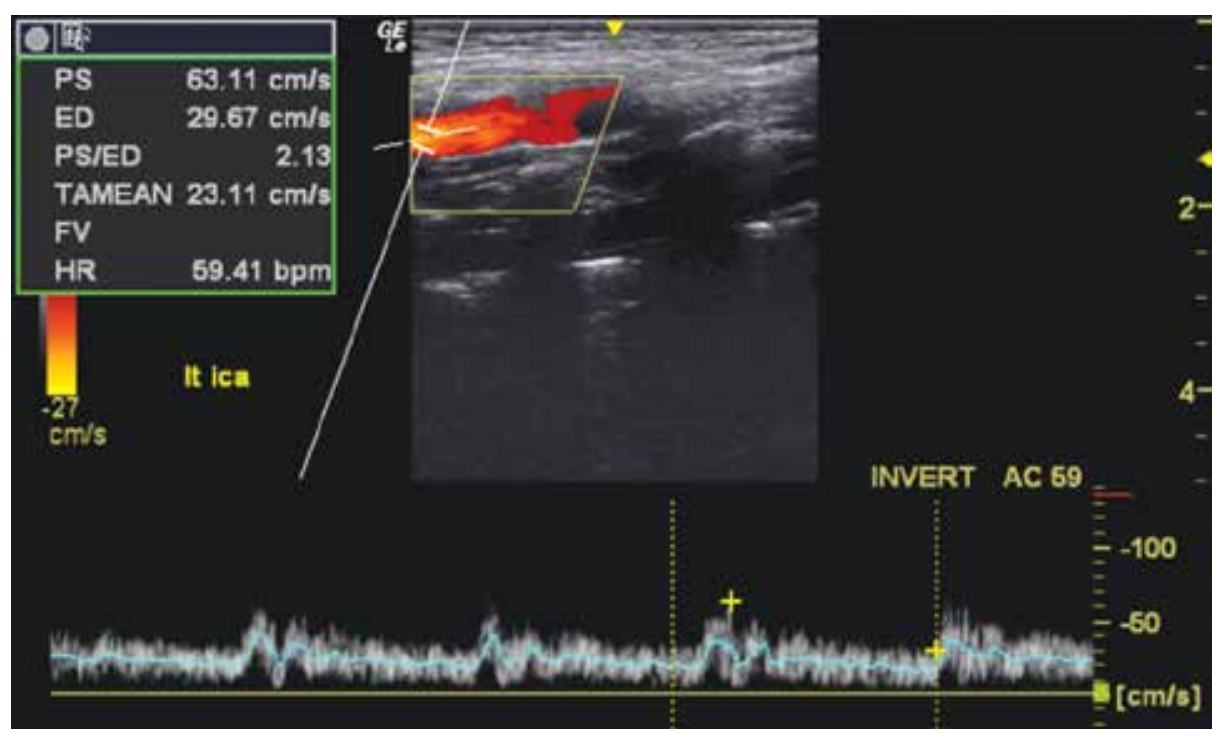

Figure 5: A 23-year-old female patient with very severe TOS and near paresis of the left arm due to plexopathy. Duplex examination of the ipsilateral axillary artery revealed near-occlusion in the military brace test-position. Ipsilateral internal carotid artery shows a severely dampened systolic peak, suggesting severe congestion and loss of luminal compliance during the systolic phase. Her right arm, as such, had normal strength, and ICA on this side had moderate "pyramidal" appearance as seen in earlier Figures.

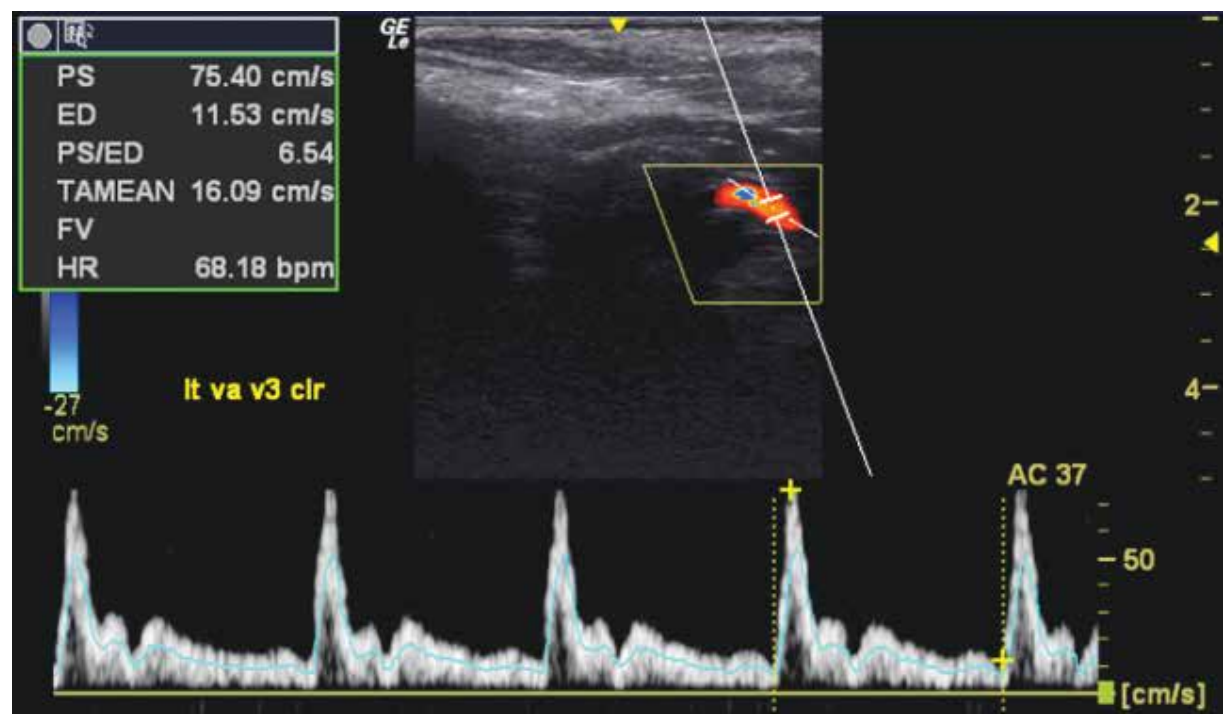

Figure 6: Duplex examination of the distal V3 segment of the vertebral artery in a patient with TOS and suspected vertebrobasilar insufficiency revealed tremendous pulsatility suggestive of hyper-, rather than hypoperfusion, in both left and right cervical rotation.

To reliably detect proximal flow obstruction in the $\mathrm{VA}$, as seen in scalenogenic strangulation or BHS, with Doppler ultrasonography, the VA should be measured at the supra-atlantal (distal V3) VA segment in both the neutral position as well as in ipsilateral and contralateral cervical rotation (Figure 6). Sole V2 segment measurement does not suffice. First of all, because BHS requires measurements to be performed distal to the site of obstruction, i.e. distal to the atlantal transverse foramen, and, secondly, because studies have shown imaging possibility for normal perfusion rates even in VA dissection, ${ }^{82}$ the examination's sensitivity increases when the lumen is examined as far cranially as possible. MR or CT Angiographies with cervical rotation will demonstrate filling defects in actual VA obstruction, whereas in CVH, it will show abnormally high signal-intensities rather than focal hypointensity suggestive of obstruction. With Doppler ultrasonography, in mere minutes, these rare 


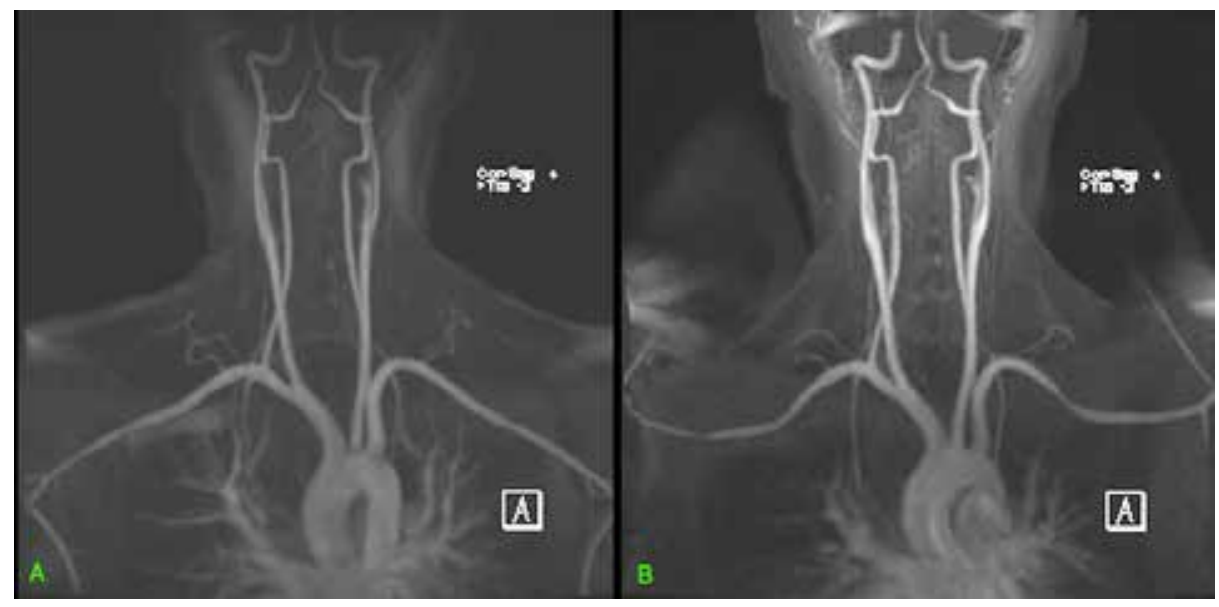

Figure 7: A 22-year-old female with longstanding TOS and chronic migraine, dizziness, and fatigue. 3D rendered MRA reveals slight subpectoral space narrowing in a neutral posture (A). However, multifocal areas of signal loss within the subclavian arteries are noted upon elevation of the arms, and direct illumination of the carotid arteries occurs due to retrograde flow of contrast-infiltrated blood.

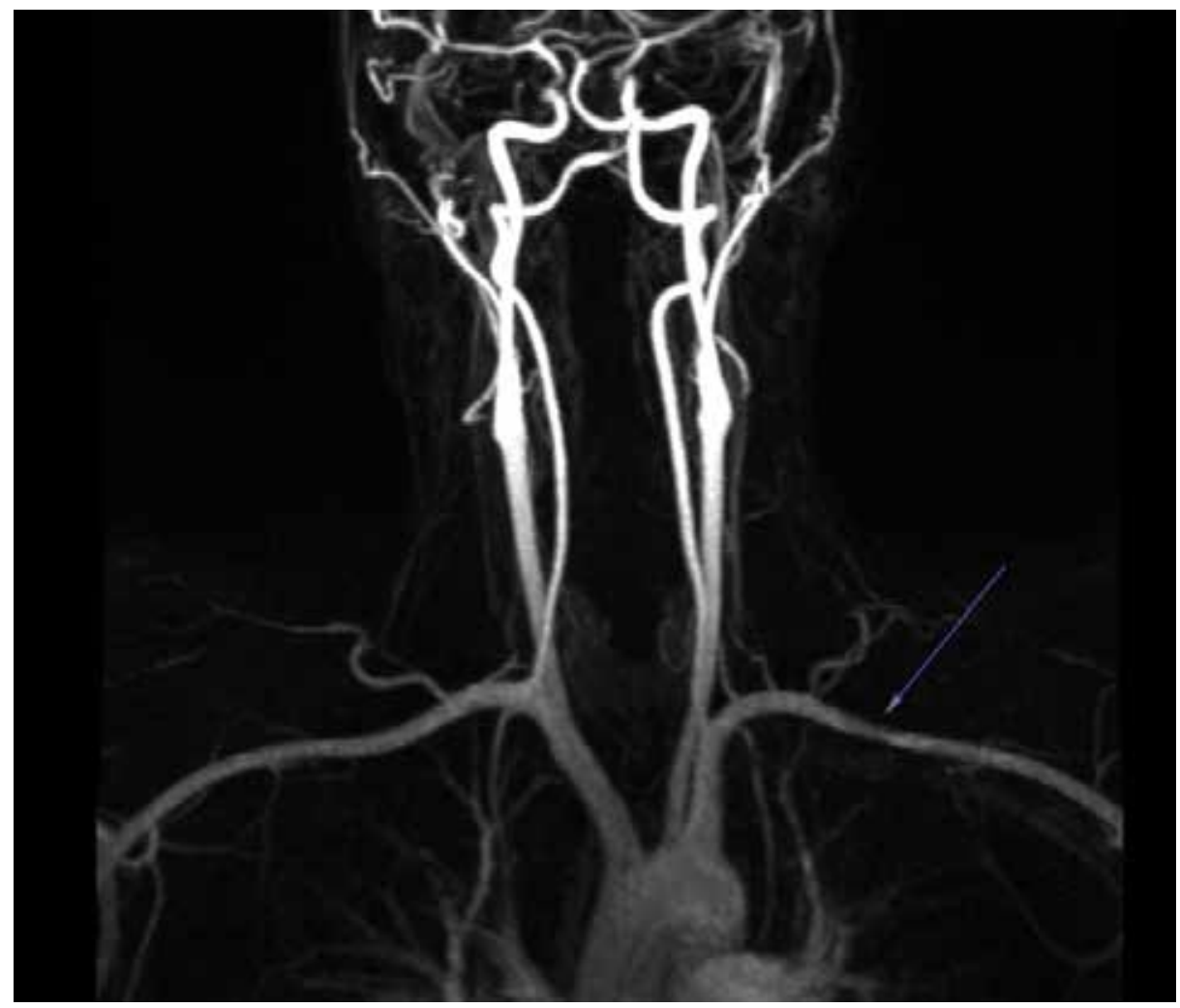

Figure 8: A 36-year-old male with chronic migraine, sporadic syncopal events, seizures, extreme fatigue, and vertigo. Plain, supine MRA reveals significant obstruction of the left subclavian artery at the costoclavicular passage, and conspicuous hyperintensity of the vertebral and carotid arteries at the cervicothoracic transition, which clearly delineates themselves from the caudal vascular anatomy, suggesting hypersaturation and congestion. Clinically, this patient's exam suggested bilateral TOS. However, there was also concurrent bilateral obstruction of the internal jugular veins, explaining the bilateral hyperintensity. but serious pathologies can be quite reliably excluded.

\section{Magnetic resonance angiography}

A contrast-enhanced, or contrast-free "time of flight" (TOF) 3D rendered MRA may demonstrate asymmetrical intensities within the carotid and vertebral arteries compared to the subclavian and aortic vasculature in TOS patients, as seen in Figure 7 \& 8. In patients with serious TOS-CVH affliction, mere neck extension will suffice in bringing forth the abnormal signal increase in the extracranial arteries. In patients with a lesser degree of vascular TOS, however, provocative maneuvers may be necessary to demonstrate the asymmetrical luminal intensities. Patients with predominant scapular dyskinesia or pronounced pectoralis minor tightness will most likely demonstrate pathology upon brachial elevation. Forced clavicular depression ("military brace test") will subsequently be done if the elevation maneuver is negative, as this compresses the subclavian artery in patients with TOS. ${ }^{72}$ The purpose of this maneuver is not necessarily to detect obstruction of the subclavian artery, but, more importantly, to detect signal intensity increase in the VA and ICAs either in neutral position or in provocative maneuver, suggestive of TOS CVH.

2D slices are not sensitive for delineating intensity differences between normal and abnormal 
vasculature, and thus a 3D rendered MRA is preferred over 2D MRA or CTA. There may or may not be conspicuous luminal narrowing in the subclavian arteries seen on MRA. Lacking frank subclavian obstruction does not exclude CVH. Even severe scalenus tightness does usually not cause [significant] filling defects within the subclavian artery, on MRA, but may still cause severe CVH. Doppler ultrasonography may also be used when evaluating the axillary artery, but this will not allow simultaneous evaluation of relative intensities between the subclavian and extracranial arteries.

\section{E. Neuro- ophthalmological examination}

The retina may provide subtle information with regards to occult hypertensive pathology. Early findings may be retinal venous distention and loss of spontaneous venous pulsations of the central retain vein. Subtle cotton wool spots (retinal ischemic spots) are somewhat common findings in patients in TOS, and suggests early hypertensive retinopathy. ${ }^{56,57,58}$ More aggressive signs include arteriovenous "nicking", copper- or "silver wiring", arteriolar constriction, papilledema, and optic disk elevation, suggesting significant, longstanding hypertension. Moreover, the neuro-ophthalmic examination may frequently demonstrate nystagmus, diplopia, or impairment of convergence which

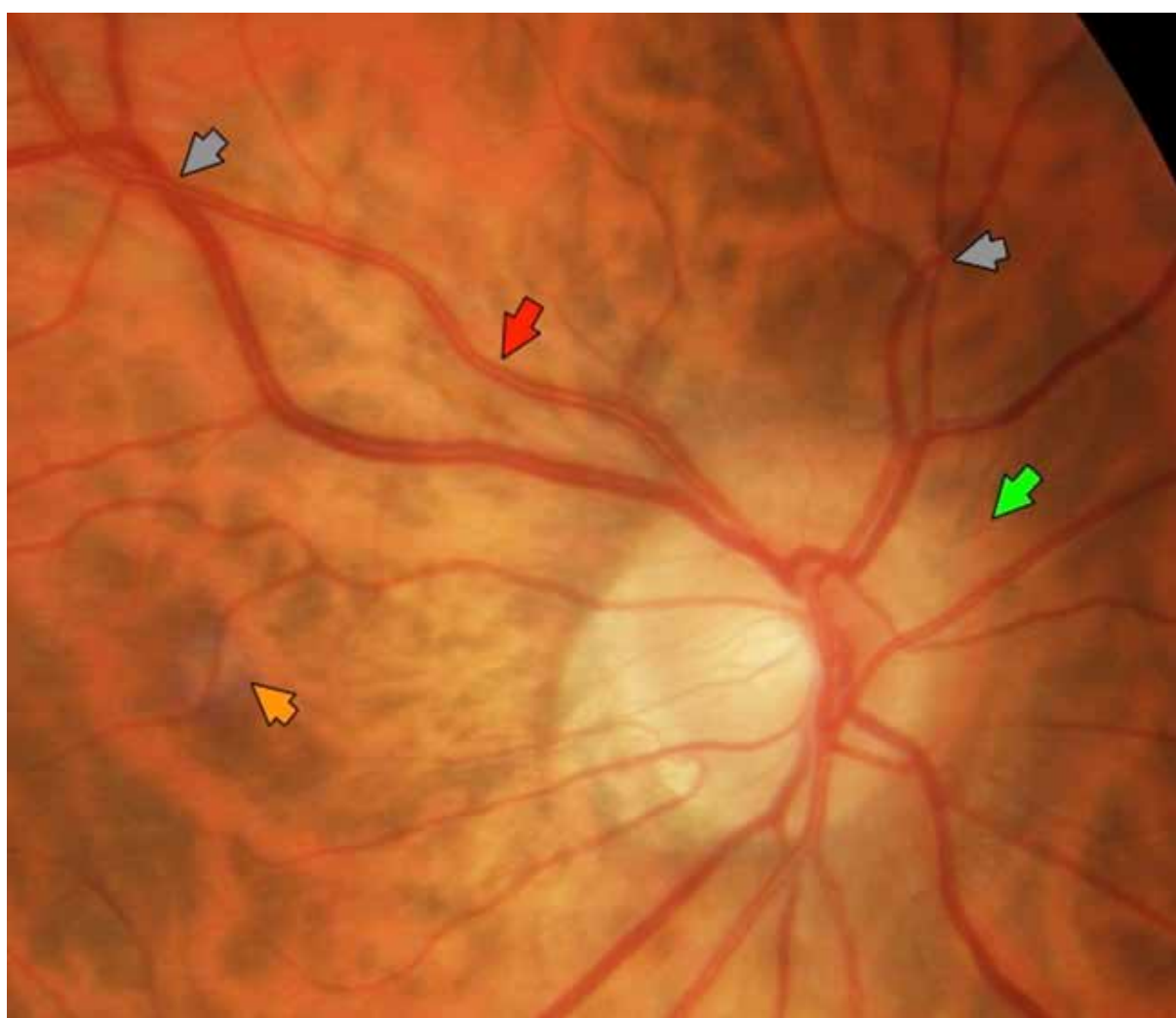

Figure 9: Subtle hypertensive retinal appearance in a 43-year-old female patient with pronounced systemic hypotension $(90 / 60 \mathrm{mmHg})$ and concurrent, severe TOS. Slight optic disk elevation is seen along with blurring of its nasal borders (green arrow). Moreover, copper wiring (red arrow), early arteriovenous "nicking" (gray arrows) and focal retinal ischemia ("cotton wool spot") nasal to the macula (orange arrow).

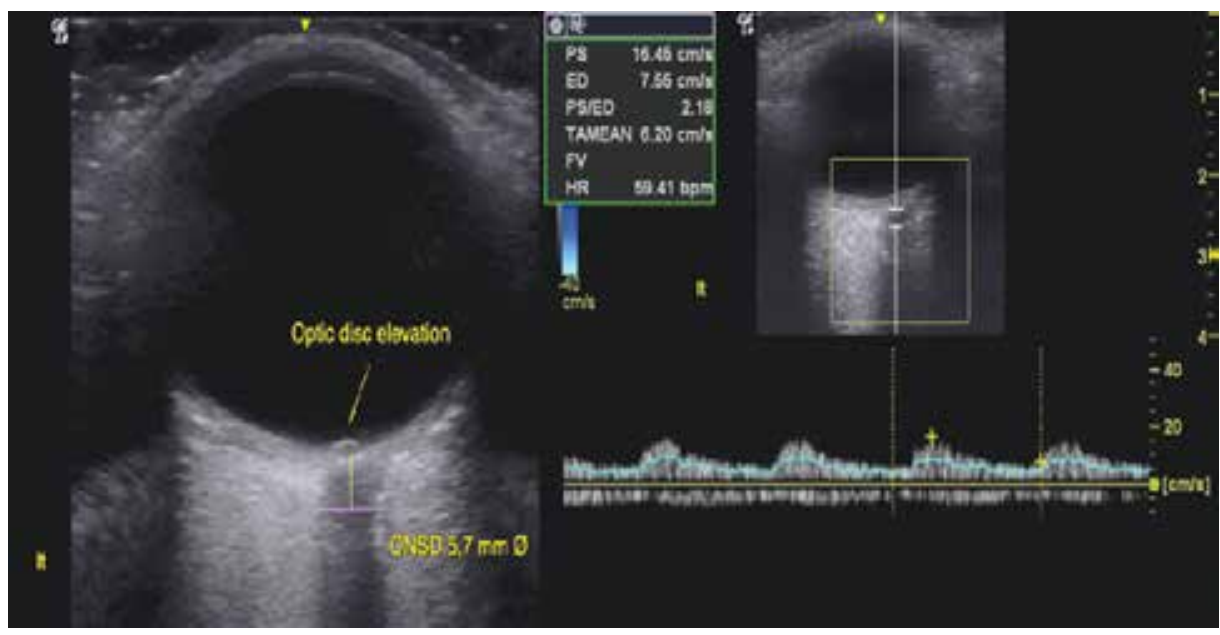

Figure 10: Orbital ultrasonography reveals papilledema in a patient with chronic migraine, memory loss, and upper extremity pain. Normal brachial blood pressure and cerebral MRI. There is a relatively normal diameter of the optic nerve sheath, i.e. no suspicion of concurrent venogenicity. Retinal Doppler examination, however, demonstrated severely slowed systolic upstroke and rounded peaks. The flow velocities are normal,84 and thus these findings are manifestations of hypertension and should not be interpreted as tardus parvus (hypoperfusion). An ophthalmologist later confirmed hypertensive appearances of the retina upon fundoscopy. 
worsens in provocative position. The patient may experience nystagmus when their eyes are closed when lying in neck extension, but not when side-lying and in neck flexion. The vestibuloocular reflex may often be impaired.

\section{F. Orbital ultrasonography}

Transorbital ultrasonography may demonstrate papilledema with disk elevation despite a normal optic nerve sheath diameter, suggesting arterial hypertension rather than excess cerebrospinal fluid. Pathological CSF levels will cause concomitant optic nerve sheath dilation $>5,8 \mathrm{~mm} \emptyset$ in the majority of incidences. ${ }^{83}$

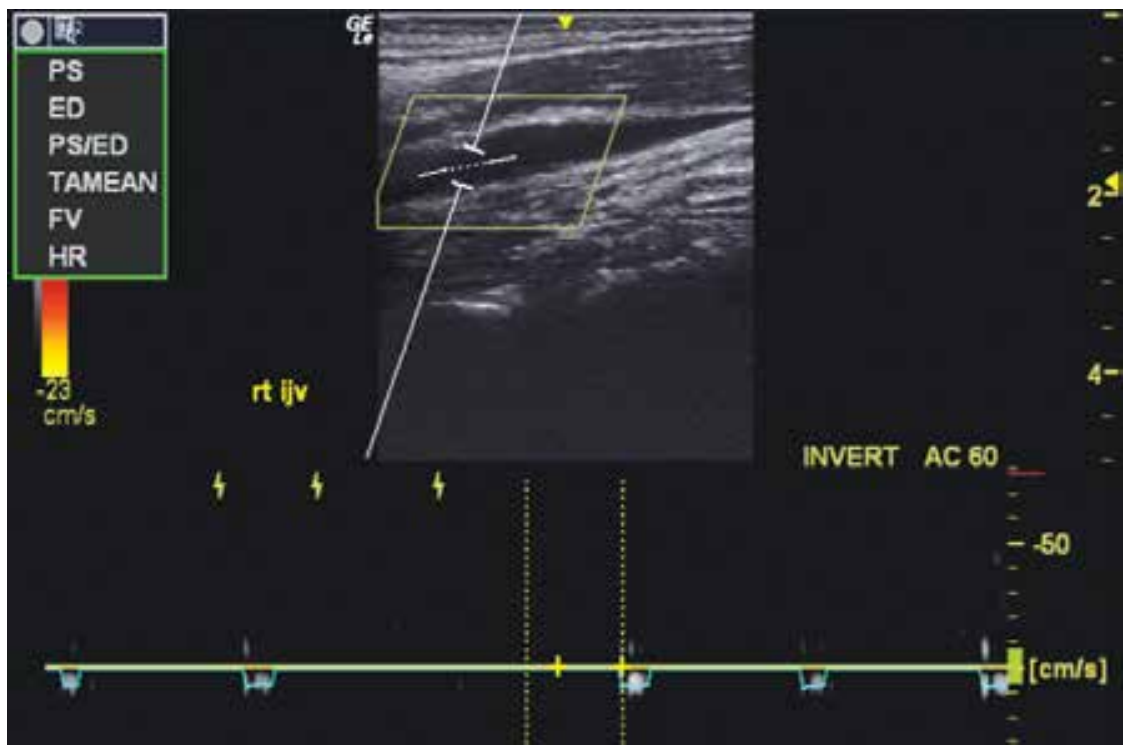

Figure 11: Absence of flow in the right internal jugular vein, in a patient with brachialgia, asthenia, and migraines. Normal unilateral flow volumes tend to span between $350-700 \mathrm{ml} / \mathrm{min}$.

Such conclusions should, however, not be drawn unless everything else points in that very same direction. Be aware that the mechanical index should be set to no more than 0,23 when examining the eyes ultrasonographically. ${ }^{85}$

\section{G. Exclusion of venogenic causes}

An impaired cerebrovenous drainage capacity will also cause craniovascular congestion and cause similar symptoms to that seen in TOS CVH. Recent research has shown that cerebrovenous drainage impairment is a problem of much higher prevalence than earlier considered. ${ }^{86,87}$ A simple Doppler scan with volume flow measurements of the internal jugular veins will help in excluding venogenic causes of the patient's problems, and can be done in mere minutes. Normal volume flow quantities amount to approximately $700-1000 \mathrm{ml} / \mathrm{min}$ both sides combined. ${ }^{88,89,90}$ Even the hypoplastic side should drain around $300 \mathrm{ml} / \mathrm{min},{ }^{90}$ and unilateral flow-deficit should not automatically be rendered insignificant if the opposite canal demonstrates seemingly adequate perfusion. Flow rates lower than $160 \mathrm{ml} / \mathrm{min}$ may suggest thrombosis or significant stenosis. ${ }^{90}$ We have seen that cerebrovenous drainage deficits are often concurrent in patients with TOS. In these cases, an evaluation should be done to estimate which problem has the most likely etiology. Often both issues must be addressed. In cerebrovenous drainage impairment, optic nerve sheath dilation hgher than $5,8 \mathrm{~mm}$ in diameter may be expected, but papilledema is not always present despite co-presence of pathological CSF levels. ${ }^{11}$

\section{TREATMENT OF TOS-INDUCED CVH}

Both palliative and etiologically focused treatment approaches should be used when treating TOS induced $\mathrm{CVH}$. Pharmacological and daily positional considerations may ameliorate the patient's symptoms. Concurrently, addressing its underlying causes should be done. This part will also discuss some important crucial contraindications, along with a brief detailing of palliative and etiological treatment approaches.

\section{A. Conservative considerations}

The main aim in conservative therapy is to alleviate neurovascular compression in the interscalene, costoclavicular, and subpectoral spaces. It is essential that common treatment fallacies that promote scapular retraction and depression, as well as scalene muscle stretching, are avoided, as these, although temporary relief may sometimes be experienced, will exacerbate the condition long-term. ${ }^{71,72,73}$ The patient should be cued to keep their shoulders up in posture, at least one centimeter higher than that of maximal depression, to decompress the costoclavicular space and disengage the pectoralis minor, as well as gently strengthen their scalenus anticus and medius muscles twice per week. ${ }^{71,72}$

With regard to palliative considerations, cerebral blood flow increases significantly when supine. ${ }^{92}$ The patient should, therefore, rest in slight inclination, preferably side-lying and in cervical flexion. This will reduce the CVH and improve their quality of sleep. Contrarily, sleeping supine on a small or with 
special article

no pillow at all will severely exacerbate the $\mathrm{CVH}$ due to tautening of the scalenus anticus.

Further: Strength training of the upper extremities will cause increased upper extremity blood consumption rates in up to 72 hours after adequately intensive exercise. The increased peripheral perfusion rates may significantly reduce brachial resistance and will thus ameliorate the $\mathrm{CVH}$ for 24-72 hours depending on how hard the patient trained and their amount of muscle mass. Scapular dyskinesia, if present, must be treated prior to the initiation of intensive strength training, as dyskinesia may grossly exacerbate their symptoms due to consequent costoclavicular narrowing. Likewise, reducing cervical extension during exercise will reduce potential scalenus muscle compression of the subclavian artery and thus also relieve the physical vascular obstruction, reducing their symptoms.

Contraindications: Cervical manipulative procedures are commonly performed in patients with chronic neck pain. However, TOS induced CVH will rigidize the VA due to hypersaturation, and this may make the patient more susceptible to VA injury secondary to high-velocity manipulation. It is known that patients with hypertension are more susceptible to VA dissection. ${ }^{93}$ Moreover, VA dissection is a rare but acknowledged potential adverse effect of cervical manipulation. ${ }^{94}$ We believe that cervical manipulation should be regarded as contraindicated in patients with TOS and pronounced craniological co-morbidities.

\section{B. Pharmacological measures}

A consensus on the appropriate pharmacological regimen for TOS remains controversial, and it varies according to the underlying etiology of TOS. Generally, pharmacological interventions are indicated for the control of pain and neurological symptoms, for muscle relaxation or for thromboembolic complications or prophylaxis, ${ }^{95-102}$ but no preexisting protocol for cerebrovascular hyperperfusion forelies in the literature. Therefore, we present our recommendation based on the treatment of other similar conditions and our clinical experience.

The first step is to examine the patient's blood pressure. Maintaining normal blood pressure values could be beneficial and reduce, albeit partially, TOS symptoms. No studies demonstrating the superiority of a class of antihypertensives, so we refer the choice of the drug (ace inhibitors, sartans, etc.) to the clinician's experience. Diuretics can be used both in association with antihypertensives as add-on therapy or as needed to reduce TOS related symptoms. The most commonly used diuretics are:

- Thiazides: Hydrochlorothiazide
- Loop diuretics: Furosemide or torsemide

- Carbonic anhydrase inhibitors: acetazolamide

- Potassium-sparing agents: amiloride

Based on our experience, the administration of medium-low doses of hydrochlorothiazide plus amiloride, are effective in reducing the continuous symptoms related to hyperperfusion, while acetazolamide can be used in sporadic acute attacks.

In the most severe cases and especially at the beginning of treatment, it may be beneficial to combine antiedematous corticosteroids, such as dexamethasone. Prednisone or methylprednisolone can obviously be used but we prefer dexamethasone, especially drops formulations that can be easily dosed.

Among the pharmacopoeia generally indicated in the treatment of TOS, we can find all the drugs that, variably based on symptoms, can be added to the therapy of forms with cerebrovascular hyperperfusion, and are:

Non-opioid analgesics. Nonsteroidal antiinflammatory drugs commonly are prescribed in patients with mild to moderate pain to control symptom flare. They inhibit inflammatory reactions and pain by decreasing prostaglandin synthesis. Acetaminophen is a safe choice for gastrointestinal, kidney or cardiovascular complications as well as during pregnancy or breastfeeding. ${ }^{95}$

Opioids. Generally prescribed in chronic or longstanding disease or in short-term for symptom flares as well as for post-surgery. Low to mild dose opioids can be used as ground therapy in moderate to severe pain. Transdermal opioids are generally well accepted and can enhance patient's adherence to the treatment. ${ }^{95}$

Opioids antagonist. Generally used to manage alcohol or opioid dependence. Naltrexone is a reversible competitive antagonist at $\mu$-opioid and $\kappa$-opioid receptors. However, it was discovered that its use in low doses follows alternate pharmacodynamic pathways with various effects. Low dose naltrexone has gained popularity as an off-label treatment of several autoimmune diseases including multiple sclerosis and inflammatory bowel disease, as well as chronic pain disorders including fibromyalgia, complex regional pain syndrome, and diabetic neuropathy and, in our experience, is helpful also in TOS.

Antidepressants and reuptake inhibitors. This group of drugs is commonly used and well-studied in the treatment of chronic and neuropathic pain. Tricyclic antidepressant has more cardiovascular adverse effects than serotonin and serotonin and norepinephrine reuptake inhibitors and generally are considered more difficult to titrate. These drugs also 
have sedative effects that may be beneficial in these patients. $^{95}$

Anticonvulsant and gabapentinoids. Commonly used for neuropathic pain alone or as adjuvant agent. Structural derivative of GABA. Binds with high affinity to alpha2 -delta site (a calcium channel subunit). In vitro, reduces calcium-dependent release of several neurotransmitters, possibly by modulating calcium channel function..$^{96,97}$

Muscle relaxants. May prove helpful to decrease spasm and usually prescribed in chronic contractures during the rehabilitation period. Central muscle relaxants also have a sedative effect that can be beneficial in these patients. ${ }^{95}$

Anticoagulants and thrombolytics. Only prescribed in the venous or arterial subtypes of TOS to treat arterial of venous occlusions. ${ }^{98,99}$

Local injections. Injection of local anesthetic and steroids into the anterior scalene or pectoralis muscle have demonstrated varying levels of success in observational studies. Scalenii hydrodissection or blocks are a new and promising approach to the treatment of nTOS. Ultrasound guide hydrodissection is useful to decompress the connective tissue around nerves.

Others. Cannabinoids may play an important role in nTOS due to their dual effect of neuropathic pain relief and muscle relaxation. Pentoxyfilline and cilostazol may also be considered for their effect of vasodilation and platelet aggregation inhibition.

\section{Surgical intervention}

Surgical intervention should be the last resort for these patients, reserved for those with severe CVH sequelae such as seizures, debilitating dizziness, or frequent syncopal events. As mentioned earlier, it is well-known that patients with cerebral concomitant morbidities often experience resolution of these issues after surgical intervention.

First rib resection is a potentially risky procedure with limited interventional value. Firstly, because the clavicle may drop down to compress the second rib in many of these patients. ${ }^{103,104,105}$ Secondly, costoclavicular compression is easily manageable conservatively by raising the scapulae in posture and treating scapular dyskinesia. ${ }^{72}$ We believe that salvaging the first costal is a viable choice which also reduces the likelihood of intra-procedural [iatrogenic] nerve damage. Removal of the scalenus anticus will free the subclavian artery in the interscalene triangle, significantly reducing $\mathrm{CVH}$. Removing the scalenus anticus will, further, reduce cranial pulling of the first costal, widening the costoclavicular interval. ${ }^{71}$ The scalenogenic subclavian obstruction is more constant and thus, often, more debilitating than the positional obstruction occurring in the subpectoral and costoclavicular passages, in CVH.

Small cervical ribs are usually asymptomatic and do not require surgical resection. In circumstances where the cervical rib is very large and physically indents the subclavian artery, resection may be feasible. Sometimes the cervical rib ossifies during adolescence, and if the symptoms appear in the very same period, the likelihood of it being symptomatic is high.

After scalenectomy, the patient should be referred to a qualified physiatrist who understands the pathophysiology of TOS. Cueing these patients to depress the scapulae posturally will, reiterated, grossly exacerbate their condition even after surgery, and must be avoided at all costs. The surgeon should ensure that the patient's conservative health care provider understands this crucial concept.

\section{Psychological support}

Many patients with TOS suffer from pre-existing anxiety, neuroticism, and similar psychological disorders. Moreover, although we do not believe that TOS is strictly psychogenic, treating such issues, if present, is crucial to help the patient recover. As always, non-organic (purely psychogenic) causes of pain should be differentiated from actual, organic pain-generating pathologies. Patients with TOS have a tendency of holding their breaths and physically bracing themselves (habitually "clenching" their muscles), and these unfortunate habits must be ceased.

\section{CASE REPORT}

A 23-year-old female patient presented in the first author's clinic with brachialgia, periscapular \& chest pain, dyspnea, fatigue and frequent migraines since the age of twelve. The migraines, as such, responded positively to triptans and was considered a primary migraine disorder. She also suffers from mild anxiety disorder. Her pain problems had set her on the verge of losing her employment.

She has a healthy body habitus and is approximately 170 centimeters tall. Systemic blood pressures were slightly hypotensive, at 110/70, with a resting heart rate of 65 beats per mine. The postural assessment showed poor cervical posture along with severe winging of both scapulae as well as maximal clavicular depression. Roos', Halstead's, and Morley's tests were all conspicuously positive, and the patient explains that her symptoms significantly exacerbate after carrying heavy objects, suggestive of TOS with a dominant costoclavicular component. There was an absence of deep tendon reflexes in both upper extremities. Selmonosky's white hand sign seemingly was negative, but the patient complains of 
"always" having cold hands. Upon myotome testing, pronounced weakness (grade three) was demonstrated of the right fifth finger and finger abduction (C8, T1, ulnar nerve) as well as grade four weakness of the triceps (C7, radial nerve) and shoulder abduction (C56, axillary nerve), suggestive of plexopathy, and consistent with the positive TOS tests. Cervical MRI was normal.

Internal jugular vein measurements revealed completely normal flow rates of $560 \mathrm{ml} / \mathrm{min}$ of the right (dominant) and $370 \mathrm{ml} /$ min of the left (hypoplastic) sides. Waveform examination of the internal carotid artery, however, revealed hypertensive waveforms in the neutral position, which normalized in cervical flexion and contralateral rotation (as this relaxes the scalenii). The patient felt a substantial increase in intracranial pressure after mere seconds in the cervical extension test.

Fundoscopy showed subtle ischemic (cotton wool) spots around the macula and superior retinal artery, suggestive of mild hypertension. Transorbital ultrasonography showed normal optic nerve sheath diameters of $\varnothing 4,9 \mathrm{~mm}$ left and $5,5 \mathrm{~mm}$ right side, but with some elevation of the papilla. Doppler examinations of the axillary artery showed some velocity loss but no evidence of severe, monophasic waveforms (not shown). Thus, this was a moderate case of TOS with concomitant $\mathrm{CVH}$ without significant brachiovascular compromise.

The patient was sent home with postural corrections for the head and neck, scapular repatterning as well as strengthening exercises for the scalenii. . $^{71,72}$ The author received an email from the patient three weeks later, saying that she felt better and had not suffered any headaches since the TOS CVH.

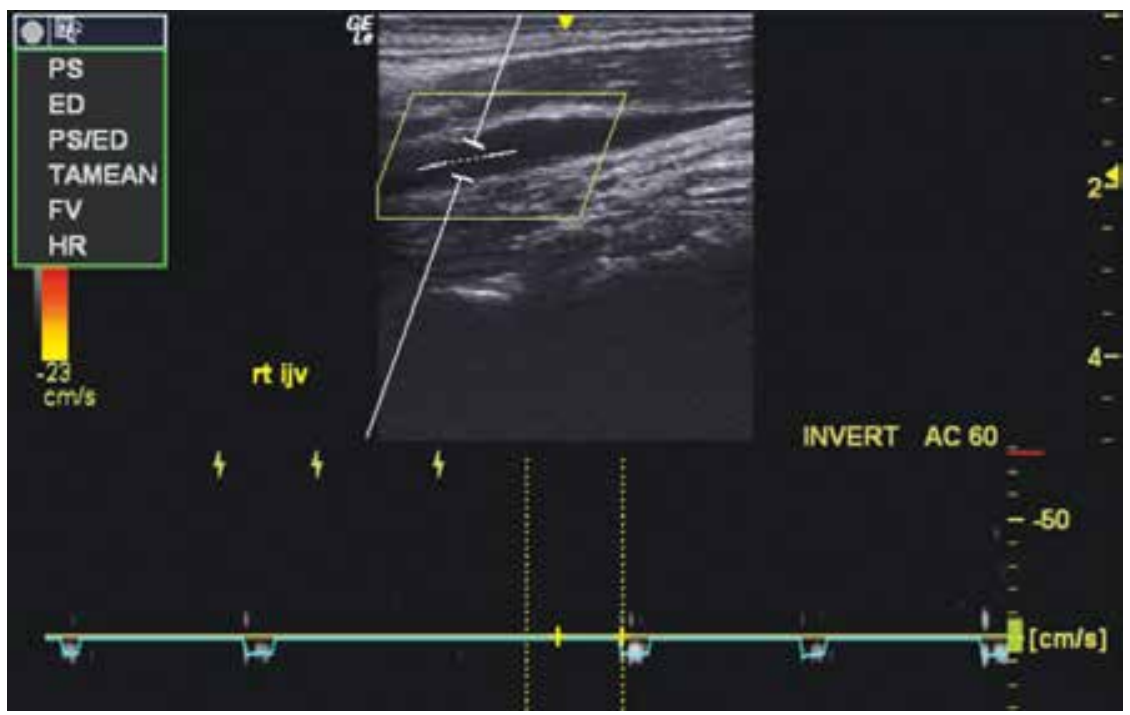

Figure 11: Absence of flow in the right internal jugular vein, in a patient with brachialgia, asthenia, and migraines. Normal unilateral flow volumes tend to span between $350-700 \mathrm{ml} / \mathrm{min}$.

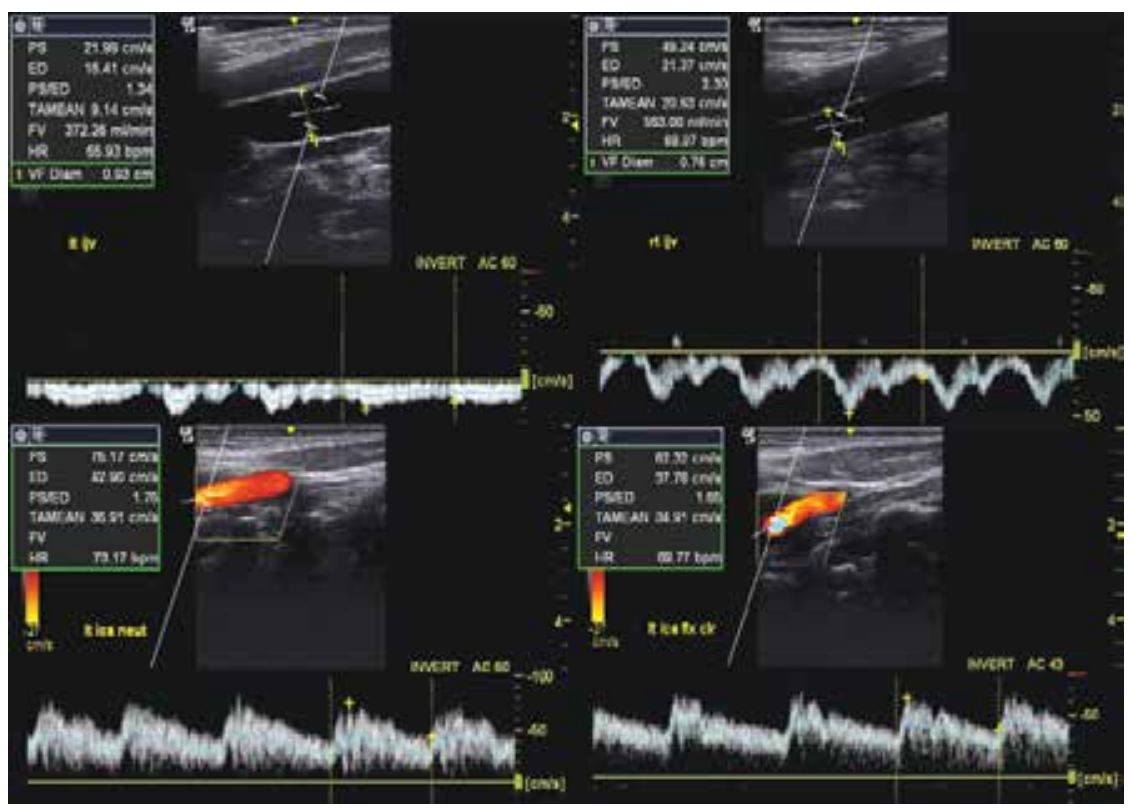

Figure 12: Upper left: Left, hypoplastic internal jugular vein drains $372 \mathrm{ml} / \mathrm{min}$. Upper right: Right, dominant IJV drains $563 \mathrm{ml} / \mathrm{min}$, and thus total IJV drainage equates to $935 \mathrm{ml} / \mathrm{min}$; perfectly normal. Lower left: Doppler waveforms in neutral position (lying supine, head straight, neck resting on a small pillow) revealed hypertensive waveforms with slowed systolic upstrokes and rounding of the systolic peaks, as well as loss of the spectral window, suggestive of turbulence. Lower right: Decent normalization of the waveforms and spectral window after setting the patient in cervical flexion and contralateral rotation, to relax the scalenus anticus. This was

examination. A follow-up email three months later showed that the patient had been pain-free for two months and had stopped all pain medications. She had suffered no migraine attacks since the initial consultation. Today she remains fully employed and pain free. 


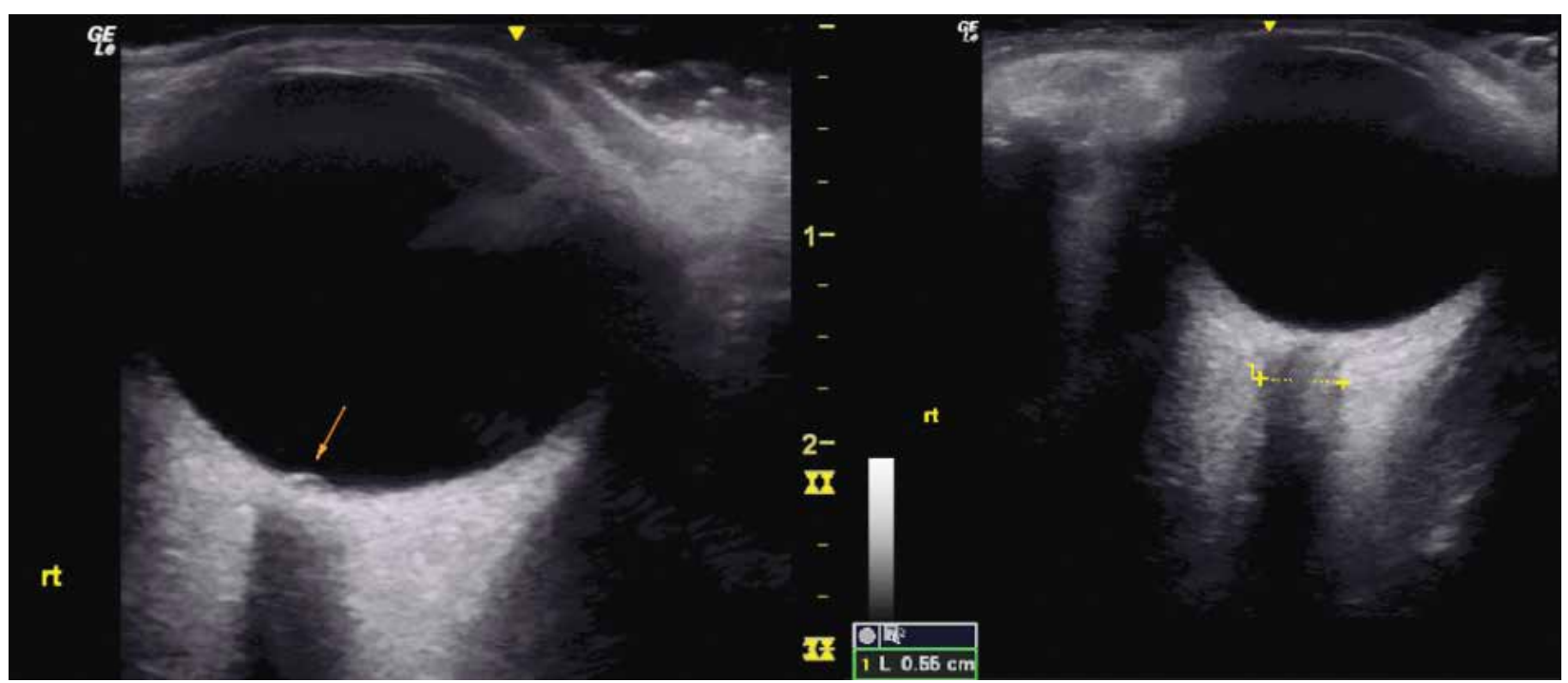

Figure 13: Papillary elevation despite a normal optic nerve sheath diameter and normal cerebrovenous drainage abilities, suggestive of arterial hypertension. The patient's serology was normal and thus no systemic etiologies were suspected.

\section{CONCLUSION}

We propose the notion that obstruction of the distal subclavian artery, as seen in thoracic outlet syndrome, may force retrograde flow of the blood that is inhibited from entering the brachium toward the head via the vertebral and carotid arteries. This results in cerebrovascular hyperperfusion and congestion, and may explain in the many craniological concomitant morbidities seen in thoracic outlet syndrome, such as dizziness, headaches, migraines, asthenia and tinnitus. In severe incidences, seizures and syncopal events may occur. TOS CVH is an occult pathology; systemic blood pressures will frequently appear normal or even hypotensive due to compensatory bradycardia and peripheral vasodilation. A significant degree of clinical suspicion is required, and the clinician who performs the exams should be versed in multiple diagnostic approaches, as seen in the article. Many of the subtle findings in CVH may be deemed as "normal variants" by an unsuspecting clinician. Systemic causes, as well as potential arterial or venous obstructive pathologies, should be excluded before rendering the TOS CVH diagnosis.

\section{Study limitations}

Lacking, direct, existing evidence, in combination with the inconspicuous diagnostic signs of TOS $\mathrm{CVH}$, are the two most significant limitations of this article.

\section{Conflict of interest}

Nil

\section{Authors' contribution:}

$\mathrm{KL}$ : Concept, manuscript formulation except pharmacology, conduction of the study work and manuscript editing

FG: formulating part on pharmacology, editing

SKC: Guidance, editing 
special article

\section{REFERENCES}

1. Sanders RJ, Hammond SL, Rao NM. Diagnosis of thoracic outlet syndrome. J Vasc Surg 2007 Sep;46(3):601-4. [Free Full Text]

2. Sanders RJ, Hammond SL, Rao NM. Thoracic outlet syndrome: a review. Neurologist 2008 Nov;14(6):365-73. DOI: 10.1097/ NRL.0b013e318176b98d. [PubMed]

3. Urschel Jr HC, Razzuk MA. Upper plexus thoracic outlet syndrome: optimal therapy. Annals of Thoracic Surgery 1997;63(4):935-9. [Free Full Text]

4. Urschel HC, Razzuk MA, Hyland JW, et al. Thoracic Outlet Syndrome Masquerading as Coronary Artery Disease (Pseudoangina). The Annals of Thoracic Surgery 1973;16(3): 239248. [Free Full Text]

5. Urschel HC Jr, Kourtis H, Jr. Thoracic outlet syndrome: a 50 year experience at Baylor University. Proc Bay Union Med Cent 2007 Apr;20(2):125-135. [Free Full Text]

6. Sanders RJ, Pearce WH. The treatment of thoracic outlet syndrome: a comparison of different operations. J Vasc Surg. 1989 Dec;10(6):626-34. [Free Full Text]

7. Sanders RJ, Haug CE. Thoracic Outlet Syndrome: A Common Sequela of Neck Injuries. Published by Richard J Sanders MD, 1991.

8. Sanders JR. Neurogenic Thoracic Outlet Syndrome and Pectoralis Minor Syndrome: A Common Sequela of Whiplash Injuries. Journal for Nurse Practitioners. 2008;4(8):586-9 [Free Full Text]

9. Washington University school of Medicine. "Neurogenic TOS". http://tos.wustl.edu/For-Patients/ Neurogenic-TOS. Accessed 24 $4^{\text {th }}$ of November, 2018.

10. Sell JJ, Rael JR, Orrison WW. Rotational vertebrobasilar insufficiency as a component of thoracic outlet syndrome resulting in transient blindness. Case report. J Neurosurg. 1994;81:617-9 [PubMed]

11. Demos NJ, Rubenstein $\mathrm{H}$, Restivo CS. Role of scalenotomy for relief of positional vertebrobasilary ischemia. J Med Soc N J. 1980;77:419-422. [PubMed]

12. Powers SR Jr, Drislane TM, Nevins S. Intermittent vertebral artery compression; a new syndrome. Surgery. 1961 Feb;49:257-64. [Free Full Text]

13. Hardin CA, Poser CM. Rotational Obstruction of the Vertebral Artery Due to Redundancy and Extraluminal Cervical Fascial Bands. Annals of Surgery. July 1963;158(1):133-137 [Free Full Text]

14. Husni EA: Mechanical occlusion of the vertebral artery. JAMA 196(6):101104. 1966 [Free Full Text]

15. Riddell DH, Smith BM. Thoracic and vascular aspects of thoracic outlet syndrome. Clin Orthop. 1986;207:316. [PubMed]

16. Bacquey $F$, Hamon $M$, Coskun 0 , Coffin 0 , Joidate A, Courtheoux P, Theron J. Rotational vertebro-basilar insufficiency secondary to a fibrous band of the longus colli muscle: value of CT spiral angiography diagnosis. J. Radiol. 2002;83:979-982. DOl: JR-07-08-2002-83-7-8-0221-0363101019-ART17 [PubMed]

17. Dadsetan MR, Skerhut HE. Rotational vertebrobasilar insufficiency secondary to vertebral artery occlusion from fibrous band of the longus coli muscle. Neuroradiology. 1990;32:514-515. [PubMed]

18. Kuether TA, Nesbit GM, Clark WM, Barnwell SL. Rotational vertebral artery occlusion: a mechanism of vertebrobasilar insufficiency. Neurosurgery. 1997;41:3. [PubMed]

19. Shimizu T, Waga S, Kojima T, Niwa S. Decompression of the vertebral artery for bow-hunter's stroke. J Neurosurg. 1988;69:127-131 [PubMed]

20. Dargon PT, Liang CW, Kohal A, Dogan A, Barnwell SL, Landry GJ. Bilateral mechanical rotational vertebral artery occlusion. J vasc sur. 2013:58:10761079. DOl: https://doi.org/10.1016/j. jvs.2012.12.044 [Free Full Text]

21. Pellerito J, Polak J. Introduction to Vascular Ultrasonography 6th Edition,
2012; Elsevier publishing.

22. Arnold C, Bourassa T, Langer T, Stoneham G. Doppler studies evaluating the effect of a physical therapy screening protocol on vertebral artery blood flow. Man Ther. 2004;9:13-21. [PubMed]

23. Ozdemir $H$, Cihangiroglu $M$, Berilgen $S$, Bulut S. Effects of Cervical Rotation on Hemodynamics in Vertebral Arteries. JDMS 21:384391 September/October 2005. DOI: 10.1177/8756479305278982 [Free Full Text]

24. Mitchell J. Doppler insonation of vertebral artery blood flow changes associated with cervical spine rotation: Implications for manual therapists. $J$ physiotherapy theory practice. 2007;23:6:303-313 [PubMed]

25. Cavdar S, Dalcik H, Ercan F, Arbak S, Arifoglu Y. A morphological study on the V2 segment of the vertebral artery. Okajimas Folia Anat. 1996;73:133137. [PubMed]

26. Mitchell J. Differences between left and right suboccipital and intracranial vertebral artery dimensions: An influence on blood flow to the hindbrain? Physiother Res Internat. 2004;9:85-95. [PubMed] DOl:10.1002/pri.305

27. Saxton EH, Miller TQ, Collins JD. Migraine complicated by brachial plexopathy as displayed by MRI and MRA: aberrant subclavian artery and cervical ribs. J Natl Med Assoc. 1999 Jun;91(6):333-341. [PubMed] [Free Full Text]

28. Raskin NH, Howard MW, Ehrenfeld WK. Headache as the leading symptom of the thoracic outlet syndrome. Headache. 1985 Jun;25(4):208-10. [PubMed] DOI: 10.1111/j.15264610.1985.hed2504208.x

29. Washington University school of Medicine. "Pamela's Story". http://tos. wustl.edu/Patient-Features/PamelasStory. Accessed 24th of November, 2018.

30. Chahwala V, Tashiro J, Li X, Baqai A, Rey J, Robinson HR. Ann Vasc Surg. 2017 Feb;39:285.e5-285.e8. DOl: 
10.1016/j.avsg.2016.05.109. Epub 2016 Aug 13. Venous Thoracic Outlet Syndrome as a Cause of Intractable Migraines. [PubMed] DOI:10.1016/j. avsg.2016.05.109

31. Jensen $\mathrm{RH}$, Radojicic $A$, Yri $H$. The diagnosis and management of idiopathic intracranial hypertension and the associated headache. Ther Adv Neurol Disord. 2016;9(4):31726. [PubMed] [Free Full Text] DOl: 10.1177/1756285616635987

32. Hulens M, Rasschaert R, Vansant G, Stalmans I, Bruyninckx F, Dankaerts W. The link between idiopathic intracranial hypertension, fibromyalgia, and chronic fatigue syndrome: exploration of a shared pathophysiology. J Pain Res. 2018;11:3129-3140. DOl: 10.2147/JPR.S186878 [PubMed] [Free Full Text] DOI: 10.2147/JPR. S186878

33. Higgins JNP, Pickard JD, Lever AML. Chronic fatigue syndrome and idiopathic intracranial hypertension: different manifestations of the same disorder of intracranial pressure? Med Hypotheses. 2017;105:6-9. [PubMed] [Free Full Text] DOI: 10.1016/j.mehy.2017.06.014

34. Miller R, Kelso R. Thoracic Outlet Syndrome in a Child Presenting As Syncope. J vasc surg. 2014:60:4p1118 [Free Full Text]

35. Li Q, Tan G, Zhou J. Basilar-Type Migraine with Coma: Case Reports and Literature Review. Pain Med. 2011 Apr;12(4):654-6. DOl: 10.1111/j.1526-4637.2011.01080.x. Epub 2011 Apr 4. [PubMed] [Free Full Text] DOI: $10.1111 / \mathrm{j} .1526$ 4637.2011.01080.x

36. Urschel HC, Razzuk MA, Hyland JW, Matson JL, Solis RA, Wood $\mathrm{RE}$, et al. Thoracic outlet syndrome masquerading as coronary artery disease (pseudoangina). Ann Thorac Surg.1973;16(3):239-48 [PubMed] [Free Full Text] DOl:10.1016/ s0003-4975(10)64991-0

37. Vemuri C, McLaughlin LN, Abuirqeba AA, Thompson RW. Clinical presentation and management of arterial thoracic outlet syndrome. J Vasc Surg. 2017;65(5):1429-39
[PubMed] [Free Full Text] DOI: 10.1016/j.jvs.2016.11.039

38. Arnhjort $T$, Nordberg J, Delle $M$, Borgis CJ, Rosfors S, Larfars G. The importance of the costoclavicular space in upper limb primary deep vein thrombosis, a study with magnetic resonance imaging (MRI) technique enhanced by a blood pool agent. Eur J Intern Med. 2014;25(6):54549. [PubMed] DOI: 10.1016/i. ejim.2014.05.005

39. Fiorentini C, Mattioli S, Graziosi F, Bonfiglioli R, Armstrong TJ, Violante FS. Occupational relevance of subclavian vein thrombosis in association with thoracic outlet syndrome. Scand J Work Environ Health. 2005;31:160-163. [PubMed] DOI: 10.5271/sjweh.863

40. Meumann EM, Chuen J, Fitt G, Perchyonok Y, Pond F, Dewey HM. Thromboembolic stroke associated with thoracic outlet syndrome. J Clin Neurosci. 2014 May;21(5):886-9. DOl: $\quad 10.1016 /$ j.jocn.2013.07.030. [PubMed] DOI: 10.1016/i. jocn.2013.07.030

41. Strzelecka J, Skadorwa T, Franckiewicz M, Jó $\square$ wiak S. A case of symmetric retrograde thromboembolic cerebral infarction in an 8-year-old child due to arterial thoracic outlet syndrome. Childs Nerv Syst. 2018;34:2503. [Free Full Text] https://doi. org/10.1007/s00381-018-3911-x

42. Sharma S, Kumar S, Joseph L, Singhal V. Cervical rib with stroke as the initial presentation. Neurol India. 2010;58:645-7 [PubMed] [Free Full Text] DOI: 10.4103/00283886.68691

43. Cushing $\mathrm{H}$. Concerning a definite regulatory mechanism of the vasomotor centre which controls blood pressure during cerebral compression. Bull Johns Hopkins Hosp., 1901 12: 290-2.

44. Escott, Mark EA. "Understanding the cushing effect". Available on https:// www.jems.com/articles/2007/07/ understanding-cushing-reflex.html. (Accessed 4 October, 2018)

45. Rao DA, Tao L, Vikas B. (2007). First Aid for the USMLE Step 12008 (First
Aid for the Usmle Step 1). McGrawHill Medical. ISBN 0-07-149868 Page 254

46. Shekhar S, Liu R, Travis OK, Roman RJ, Fan F. Cerebral Autoregulation in Hypertension and Ischemic Stroke: A Mini Review. J Pharm Sci Exp Pharmacol. 2017;2017(1):21-27. [PubMed] [Free Full Text]

47. Strandgaard S, Olesen J, Skinhoj $\mathrm{E}$, Lassen NA. Autoregulation of brain circulation in severe arterial hypertension. $\mathrm{Br}$ Med J. 1973;1(5852):507-510. [Free Full Text] DOI: 10.1136/bmj.1.5852.507

48. Moulakakis KG, Mylonas SN, Sfyroeras GS, Andrikopoulos V. Hyperperfusion syndrome after carotid revascularization. Journal of Vascular Surgery. 2009;49(4):10601068. [PubMed] [Free Full Text] DOI: $\quad$ https://doi.org/10.1016/j. jvs.2008.11.026

49. Fisher CM. The arterial lesions underlying lacunes. Acta Neuropathol. 1968;12:1-15. [PubMed] DOI: $10.1007 / \mathrm{bf0} 0685305$

50. Schürks M, Rist PM, Bigal ME, Buring JE, Lipton RB, Kurth T. Migraine and cardiovascular disease: systematic review and meta-analysis. BMJ. 2009;339:b3914. [PubMed] [Free Full Text] DOI: 10.1136/bmj.b3914

51. Caplan LR. Migraine and vertebrobasilar ischemia. Neurology. 1991 Jan;41(1):55-61. [PubMed]

52. Sacco S, Ornello R, Ripa P, Pistoia F, Carolei A. Migraine and hemorrhagic stroke: A meta-analysis. Stroke. 2014;44:3032-3038. [PubMed] DOI: 10.1161/STROKEAHA.113.002465

53. Witvoet EH, Pelzer N, Terwindt GM, et al. Migraine prevalence in patients with unruptured intracranial aneurysms: A case-control study. Brain Behav. 2017;7(5):e00662. [PubMed] DOI: 10.1002/brb3.662

54. Agostoni E, Rigamonti A. Migraine and small vessel diseases. Neurol Sci. 2012 May;33 Suppl 1:S51-4. [PubMed] DOI: 10.1007/s10072012-1041-x.

55. Kurth T, Kase CS, Schürks M, Tzourio $\mathrm{C}$, Buring JE. Migraine and risk of haemorrhagic stroke in women: 
special article

prospective cohort study. BMJ. 2010;341:c3659. [PubMed] DOl: 10.1136/bmj.c3659

56. Rose KM, Wong TY, Carson AP, Couper DJ, Klein R, Sharrett AR. Migraine and retinal microvascular abnormalities: the Atherosclerosis Risk in Communities Study. Neurology. 2007 May 15;68(20):1694-700. [PubMed] DOI: $\quad$ https://doi.org/10.1212/01. wnl.0000261916.42871.05

57. Bajaj NPS, Morrish PK. The danger of ignoring a migraine. Postgraduate medical journal78:915. [Free full text] DOl: http://dx.doi.org/10.1136/ pmj.78.915.53

58. Liu G, Volpe N, Galetta S. Liu, Volpe, and Galetta's Neuro-Ophthalmology: Diagnosis and Management, 3rd Edition. Elsevier publishing, 2018.

59. Ivens S, Gabriel S, Greenberg G, Friedman A, Shelef I. Blood-brain barrier breakdown as a novel mechanism underlying cerebral hyperperfusion syndrome. Journal of neurology. 2010;257(4):615-620. [PubMed] DOI: 10.1007/s00415009-5384-z.

60. Marchi N, Angelov L, Masaryk T, Fazio V, Granata T, Hernandez N, Hallene K, Diglaw T, Franic L, Najm I, Janigro D. Seizure-promoting effect of bloodbrain barrier disruption. Epilepsia. 2007;48:732-742. [PubMed]

https://dx.doi.org/10.1111\%2Fj.15281167.2012.03637.x

61. Friedman A, Kaufer D, Heinemann U. Blood-brain barrier breakdowninducing astrocytic transformation: novel targets for the prevention of epilepsy. Epilepsy Res. 2009;85:142149. [PubMed] doi : 10.1016/j. eplepsyres.2009.03.005

62. Jha SK. Cerebral Edema and its Management. Med J Armed Forces India. 2003;59(4):326-331. DOl: 10.1016/S0377-1237(03)80147-8. [PubMed] https://dx.doi.org/10.101 6\%2FS0377-1237(03)80147-8

63. Adams RD, Vander Eecken HM: Vascular diseases of the brain. Ann Rev Med 4: 213-252, 1953. [PubMed] https://doi.org/10.1146/ annurev.me.04.020153.001241

64. Sierra C, López-Soto A, Coca A. Connecting Cerebral White
Matter Lesions and Hypertensive Target Organ Damage. Journal of Aging Research. 2011, Article ID 438978, 7 pages. [PubMed] DOI: 10.4061/2011/438978

65. Barz $H$, Schrieber A, Barz U. Demyelinating diseases as a result of cerebral edema? Medical Hypotheses Volume 104, July 2017, Pages 1014. [PubMed] DOl: 10.1016/j. mehy.2017.05.010

66. Damadian RV, Chu D. The Possible Role of Cranio-Cervical Trauma and Abnormal CSF Hydrodynamics in the Genesis of Multiple Sclerosis. Physiol. Chem. Phys. \& Med. NMR. 2011;41:1-17. [PubMed]

67. Kister I, Caminero AB, Monteith TS, et al. Migraine is comorbid with multiple sclerosis and associated with a more symptomatic MS course. J Headache Pain. 2010;11:417-425. [PubMed] DOI: $10.1007 / \mathrm{s} 10194-010-0237-9$

68. Selmonosky CA, Byrd R, Blood C, Blanc JS. Useful triad for diagnosing the cause of chest pain. South Med J. 1981;74:947-949. [PubMed] DOI: 10.1097/00007611-198108000$\underline{00015}$

69. Selmonosky CA, Silva RP. The diagnosis of thoracic outlet syndrome. Myths and facts. Revista Chilena de Cirugia 2008;60:255-261. [PubMed] DOl: $10.1016 /$ j.jvs.2007.04.050

70. Selmonosky CA. Thoracic outlet syndrome. The missing link in the diagnosis of non-coronary chest pain. Italian Journal of Cardiology 2008;9:217S.

71. Larsen K. How to truly identify and treat thoracic outlet syndrome (TOS). Web blog. Available at: https:// MSKNeurology.com/how-trulytreat-thoracic-outlet-syndrome/ [Accessed on 9 November, 2019]

72. Larsen K. Postural cues for scapular retraction and depression promote costoclavicular space compression and thoracic outlet syndrome. Anaesth Pain \& Intensive Care 2018;22(2):256267. [Free full text]

73. Larsen K, Chien GCC. Lumbosacral plexus entrapment syndrome. Part Two: Symptomology and rehabilitative trials. Anaesth pain \& intensive care 2019;23(2):138-144. [Free full text]
DOI: https://doi.org/10.35975/apic. v23i2.1056

74. Watson LA, Pizzari T, Balster S. Thoracic outlet syndrome Part 2: conservative management of thoracic outlet. Man Ther. 2010 Aug;15(4):305-14. [PubMed] DOI: 10.1016/j.math.2010.03.002

75. Kohara K, Jiang Y, Igase M, Hiwada K. Effect of Reflection of Arterial Pressure on Carotid Circulation in Essential Hypertension. AJH 1999;12:10151020. [PubMed] DOI: $10.1016 /$ s0895-7061(99)00091-6

76. Kelly RP, O'Rourke MF: Evaluation of arterial wave forms in hypertension and normotension, in Laragh $\mathrm{JH}$, Brenner BM (eds): Hypertension: Pathophysiology, Diagnosis, and Management, Laven Press, New York, 1995, pp 343-364.

77. Nichols WW, O'Rourke MF: McDonald's Blood Flow in Arteries. Theoretical, Experimental, and Clinical Principles, Arnold, London, 1998.

78. Jiang YN, Kohara K, Hiwada K: Alteration of carotid circulation in essential hypertensive patients with left ventricular hypertrophy. J Hum Hypertens 1998; 12:173-179. [PubMed]

79. Watanabe S, Okura T, Kitami Y, Hiwada K. Carotid hemodynamic alterations in hypertensive patients with insulin resistance. American Journal of Hypertension, Volume 15, Issue 10, 1 October 2002, Pages 851-856, [PubMed]

80. Weisfeldt M: Aging, changes in the cardiovascular system, and responses to stress. Am J Hypertens 1998;11: 41S-45S. [PubMed]

81. London G, Guerin A, Pannier B, Marchais S, Benetos A, Safar M: Increased systolic pressure in chronic uremia. Role of arterial wave reflections. Hypertension 1992;20: 10-19. [PubMed]

82. Larsen K. Occult intracranial hypertension as a sequela of biomechanical internal jugular vein stenosis: A case report. Anaesth Pain \& Intensive Care 2018;22(2):238-242 [PubMed]

83. Pugliese F, Crusco F, Cardaioli G, Tambasco N, Boranga B, Scaroni R, 
diagnostic markers for occult craniovascular congestion

et al. CT angiography versus colourDoppler US in acute dissection of the vertebral artery. Radiol Med. 2007 Apr;112(3):435-43. [PubMed] DOI: $10.1007 / \mathrm{s} 11547-007-0152-$ $\underline{6}$

84. Geeraerts $\mathrm{T}$, Merceron $\mathrm{S}$, Benhamou D, Vigue B, Duranteau J. Noninvasive assessment of intracranial pressure using ocular sonography in neurocritical care patients. Crit Care. 2008;12(Suppl 2):P117. [PubMed] DOI: $10.1007 /$ s00134-008-1149-x

85. Dennis KJ, Dixon RD, Winsberg F, Ernest JT, Goldstick TK. Variability in measurement of central retinal artery velocity using color Doppler imaging. J Ultrasound Med 1995 Jun;14(6):463-6. [PubMed] [Free full text] DOI: 10.7863/ jum.1995.14.6.463

86. Barnett SB. World Federation for Ultrasound in Medicine and Biology (WFUMB) Symposium on safety of ultrasound in medicine: Conclusions and recommendations on thermal and non-thermal mechanisms for biological effects of ultrasound. Ultrasound Med Biol. 1998;24:155. [PubMed] DOI: 10.1016/j. ultrasmedbio.2006.07.004

87. Jayaraman MV, Boxerman JL, David LM, Haas RA, Rogg JM. Incidence of Extrinsic Compression of the Internal Jugular Vein in Unselected Patients Undergoing CT Angiography. AJNR Am J Neuroradiol. 2012 Aug;33(7):124750. [PubMed] DOl: 10.3174/ajnr. A2953. Epub 2012 Feb 9.

88. Ding JY, Zhou D, Pan LQ, Ya JY, Liu C, Yan F, et al. Cervical spondylotic internal jugular venous compression syndrome. CNS Neurosci Ther. 2019;00:1-8. [PubMed] [Free full text]DOI:

\subsection{1/cns. 13148}

89. Müller HR, Hinn G, Buser MW. Internal jugular venous flow measurement by means of a duplex scanner. J Ultrasound Med. 1990 May;9(5):261-5. [PubMed] DOI: 10.7863/jum.1990.9.5.261

90. Brunhölzl C, Müller HR. [Doppler sonography measurement of jugular vein blood flow.] Vasa. 1990;19(1):26-
9. Article in German [PubMed]

91. Özen Ö, Ünal Ö, Avcu S1. Flow volumes of internal jugular veins are significantly reduced in patients with cerebral venous sinus thrombosis. Curr Neurovasc Res. 2014 Feb;11(1):75-82. [PubMed] DOI: $10.2174 / 15672026106661$ $\underline{31209122928}$

92. De Simone R, Ranieri A, Montella $S$, et al. Intracranial pressure in unresponsive chronic migraine. J Neurol. 2014;261(7):1365-1373. DOI:10.1007/s00415-014-7355-2 [PubMed] [Free full text] DOI: 10.1007/s00415-014-7355-2

93. Garrett ZK, Pearson J, Subudhi AW. Postural effects on cerebral blood flow and autoregulation. Physiol Rep. 2017;5(4):e13150. [PubMed] DOI: 10.14814/phy2.13150

94. Pezzini $A$, Caso V, Zanferrari $C$, et al. Arterial hypertension as risk factor for spontaneous cervical artery dissection. A case-control study. J Neurol Neurosurg Psychiatry. 2006;77(1):95-97. [PubMed] DOI: 10.1136/jnnp.2005.063107

95. Refshauge KM. Rotation: a valid premanipulative dizziness test? Does it predict safe manipulation? J Manipulative Physiol Ther 1994;17:15-19. [PubMed]

96. Jones MR, Prabhakar A, Viswanath O, Urits I, Green JB, Kendrick JB, et al. Thoracic Outlet Syndrome: A Comprehensive Review of Pathophysiology, Diagnosis, and Treatment. Pain Ther. 2019;8(1):518. DOI: 10.1007/s40122-019. 0124-2 [PubMed] [Free full text] DOI: $10.1007 / \mathrm{s} 40122-019-0124-$ $\underline{2}$

97. Wiffen PJ, McQuay HJ, Edwards JE, Moore RA. Gabapentin for acute and chronic pain. Cochrane Database Syst Rev. 2005 Jul 20. [PubMed] [Free full text]DOI: 10.1002/14651858.CD005452

98. Moore RA, Straube S, Wiffen PJ, Derry S, McQuay HJ. Pregabalin for acute and chronic pain in adults. Cochrane Database Syst Rev. 2009 Jul 8 [PubMed] [Free full text] DOI: 10.1002/14651858.CD007076. pub2
99. Brooke BS, Freischlag JA. Contemporary management of thoracic outlet syndrome. Curr Opin Cardiol. 2010;25(6):535540 [PubMed] DOI: 10.1097/ HCO.0b013e32833f028e

100. Schneider DB, Dimuizio PJ, Martin ND. Combination treatment of venous thoracic outlet syndrome: Open surgical decompression and intraoperative angioplasty. J Vasc Surg. 2004;40:599-603. [PubMed]

101. Jordan SE, Machleder HI. Diagnosis of thoracic outlet syndrome using electrophysiologically guided anterior scalene blocks. Ann Vasc Surg. 1998;12:260-264. [PubMed] DOI: $10.1007 / \mathrm{s} 100169900150$

102. Jordan SE, Ahn SS, Freischlag JA, Gelabert HA, Machleder HI. Selective botulinum chemodenervation of the scalene muscles for treatment of neurogenic thoracic outlet syndrome. Ann Vasc Surg. 2000;14(4):3659. [PubMed] DOI: 10.1007/ s100169910079

103. Foley JM, Finlayson H, Travlos A. A review of thoracic outlet syndrome and the possible role of botulinum toxin in the treatment of this syndrome. Toxins (Basel). 2012;4(11):12231235. [PubMed] DOI: 10.3390/ toxins4111223

104. Roos DB. Experience with First Rib Resection for Thoracic Outlet Syndrome. Annals of Surgery 1971:429-442 [PubMed]

105. Stallworth JM, Quinn GJ, Aiken AF. Is rib resection necessary for relief of thoracic outlet syndrome? Ann Surg. 1977 May;185(5):58192. [PubMed] [Free full text] DOI: 10.1097/00000658-19770500000011

106. Wijeratna MD, Troupis JM, Bell SN. The use of four-dimensional computed tomography to diagnose costoclavicular impingement causing thoracic outlet syndrome. Shoulder \& Elbow 2014;6(4):273275. [PubMed] [Free full text] DOI: $10.1177 / 1758573214533781$ 